\title{
Numerical analysis of frictional contact effects in push-out tests
}

\author{
Samy GUEZOULI and Alain LACHAL \\ National Institute of Applied Sciences (INSA) - Rennes - France
}

\begin{abstract}
This paper proposes an accurate and efficient 2D nonlinear finite element model to investigate the mechanical behaviour of the shear connection between prefabricated concrete slab and steel girder in composite bridges. Beside material nonlinear constitutive laws and 4-noded plane elements, frictional contact finite elements are introduced in the model at the steelconcrete interface between the girder flange and the concrete slab, between the studs and the embedding concrete and at the base of the concrete slab. Numerical results are compared against experimental results of push-out tests. The tested specimens comprise 4 or 9 studs per slab. Firstly, it is shown that 2D numerical analysis may be accurately used for simulating the original truly 3D problem: a "layer-equivalence" methodology is proposed. A numerical investigation is then carried out to study the influence of the friction coefficient on the loadslip behaviour of the specimen and the distribution of internal deformations and forces in the specimen. A parametric study and some practical recommendations could follow this numerical approach for a better design of the connection.
\end{abstract}

\section{INTRODUCTION}

A good understanding of the shear connection behavior is essential in composite construction. The first researches on this topic were carried out experimentally from push-out tests [1], [2] and [3]. They are numerous, for example for push-out tests with composite slabs and profiles steel sheeting Johnson [4] and Yuan [5] have collected 269 push-out test results!. Today, the understanding of the behavior of the shear connection with headed stud in solid slabs or in composite slabs under monotonic loading is satisfactory and currently included in design codes [6], [7]. For other types of connection or other applications, the knowledge is sometimes more limited. It is the case of grouped headed stud steel connectors used to connect prefabricated slab with girder steel flange where experimental data and studies are less numerous. First research on the topic were undertaken in Europe by Lebet [8], Roik and Hanswille [9] which gave first practical design recommendations. Few years later in Japan ([10], [11]), and in Europe ([12], [13] and [14]) other extensive studies were carried out.

Beside the experimental approaches, numerical studies were undertaken to provide an alternative to push-out tests and to allow parametric studies. Many searchers have developed 3D FE numerical models these last years but sometimes with a limited success due to the complexity of the numerical modelling of a push-out test. First 3D numerical studies started fifteen years ago with Oguejiofor and Hosain [15] to analyse push-out specimens with perfobond rib connectors. The push-out test specimen was modelled using two types of elements from the ANSYS element library: 3D reinforced concrete solid elements and membrane shell elements for structural steel of beam flanges and perfobond rib connectors. No contact-friction elements were used in this modelling. Nevertheless, coincident element nodes were either constrained or merged in function of their interaction. In addition, bilinear elements having two different stiffness values according to the relative displacement of the element were introduced. Numerical results were found in good agreement with experimental 
ones. Recently, Al-Darzi et al. [16] have developed with ANSYS software V90 a similar modelling for similar perfobond rib connections. Ten years ago, Kim et al. [17] have developed 2D and 3D FE models using LUSAS FE program to study the behaviour of through-deck welded shear connectors. The separation between the stud and the concrete on the surface of the stud shank opposite to the load was experimentally observed by Johnson and Oehlers [18] and by Jayas [19]. They showed that this phenomenon occurs at low load level and was simulated by giving zero stiffness to the coincident concrete elements with this stud shank surface. A similar method was used by Kalfas and Pavlidis [20]. Ellobody and Lam [20] have studied the behaviour of headed shear stud anchors in steel-precast composite beams. El-lobody and Young [22] have investigated the behaviour of headed shear stud anchors in composite beams with profiled steel sheeting. In these two papers non-linear finite element model with 3D solid elements (ABAQUS) was developed. The only problems of contact tackled by the authors concerns the separation between the concrete and the shear connector, on the surface of the stud shank opposite to the load. For that, differently from Kim et al. [17], coincident steel stud nodes have been detached from the surrounding concrete elements while nodes on the surface of the stud shank in the direction of loading were connected with the surrounding concrete nodes. In the same years, Okada et al. [23] have investigated the shear strength behaviour of grouped stud connectors. Based on both push-test tests and a numerical modelling, their study led to findings useful for design rules. The finite element package DIANA was used for the 3D FE-modelling. In addition to the usual solid and shell 3D elements used in such a modelling with nonlinear material properties, a bondfriction model was introduced at the interface between the steel beam and the concrete slab and between the studs and the concrete. A maximum bond stress of $0.9 \mathrm{~N} / \mathrm{mm}^{2}$ for a maximum slip of $0.05 \mathrm{~mm}$ were used by the authors in order to obtain the better agreement with experimental results. More recently, Nguyen et al. [24] have developed a refined 3D finite element model to simulate the behaviour of large stud shear connectors in push-out tests. ABAQUS finite element program was used in this analysis. The concrete slab was meshed with 8-node brick elements usable for nonlinear analysis including of contact, large deformation, plasticity and failure. A thin cohesive layer of $0.05 \mathrm{~mm}$ in thickness meshed with 8-node three-dimensional cohesive elements defined in terms of traction-separation was used between the steel flange and concrete slab of the push-out test. A tie constrain was applied to the concrete-to-stud interface. In addition a contact interaction with a friction coefficient of 0.25 was introduced at the interface between concrete slab and rigid base. After experimental calibration of the model, an extensive parametric study conducted by the authors allowed to analyse the effect of the changes of stud diameter and concrete strength on the capacity and behaviour of the shear connection. One can still underline the very recent works of Mirza and Uy [25] to study the effects of the combination of axial and shear loading on the behaviour of headed stud steel connectors. They used ABAQUS program to develop a three dimensional nonlinear finite element model. Brick elements were used for the concrete slab, structural steel beam and steel connectors. Shell elements were employed for the profile steel sheeting. Coincident concrete and steel element nodes were coupled and no contact/friction elements were introduced. This fast overview on numerical models of push-out test recently developed shows that all the main civil engineering FE codes were used alternately to develop more or less refined FE models for different types of connections. To the best knowledge of the authors, in any of the considered model, contact/friction elements able to simulate both contact/separation and friction were not introduced. A first reason is certainly the lack of accurate and efficient frictional contact algorithm in the 3D FE code libraries. Other reasons are the real computational effort and the consuming time required to develop a 3D numerical model for the analysis of a steel-concrete structure which remains always complex. It is the reason why we have try to develop an efficient nonlinear finite element model to investigate 
the influence of the contact and the friction between steel and concrete on the global behaviour of a shear connection in a push-out test. To get a better insight into the complex interaction occurring at the interface, we have taken the option to develop a 2D FE model with efficient frictional-contact algorithm. It is shown that this model is able to highlight some key phenomena occurring at the interface during a push-test. Contrarily to 3D codes worked out contact/friction elements can be easily found in 2D FE code libraries and lead to a best convergence of the iterative process. The aim of this paper is to present this new numerical approach and the effects on the global behaviour and local internal forces and deformations of the connection in a push-out test. It is expected that the results of this study will also make it possible to improve other finite element models in composite structures as for example the model developed by Guezouli S. and Yabuki T. [26] to study continuous composite beams at real scale.

\section{EXPERIMENTATION}

\subsection{The push-out test specimen}
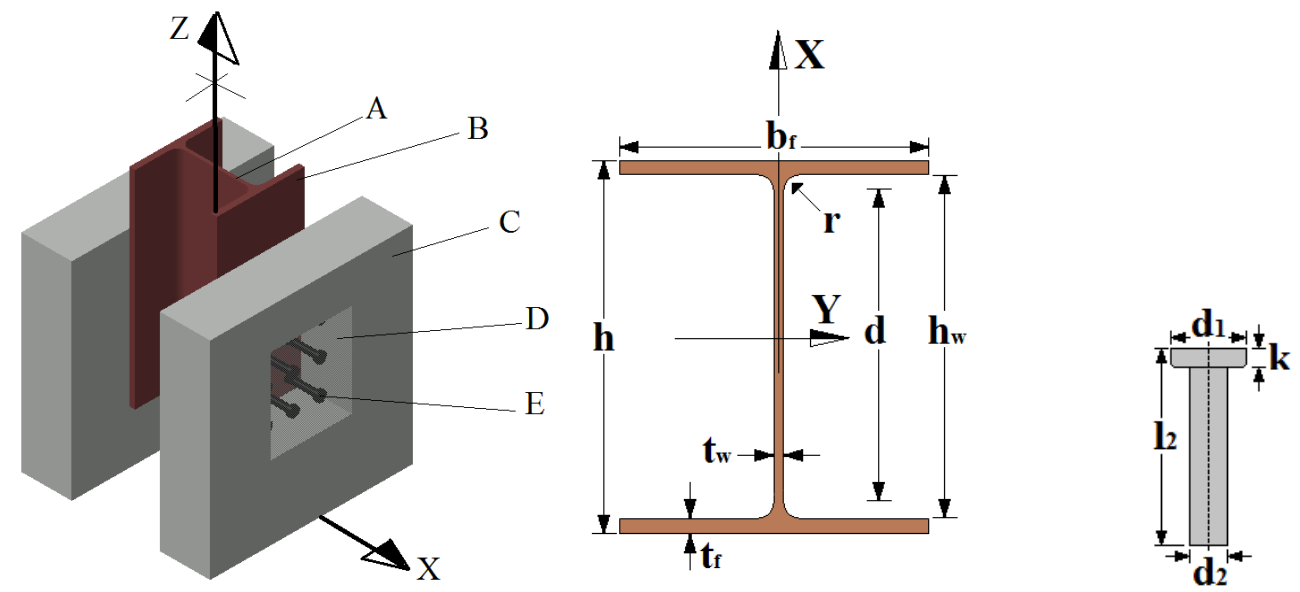

Figure 1. Push-out test specimen. Figure 2. HEB260 cross-section. Figure 3. The stud.

Table 1. Geometrical characteristics of HEB260 and stud ( $\phi 19)$.

\begin{tabular}{|c|c|c|c|c|c|c|c|c|c|c|c|}
\hline Variable & $\mathrm{h}_{\mathrm{w}}$ & $\mathrm{t}_{\mathrm{w}}$ & $\mathrm{b}_{\mathrm{f}}$ & $\mathrm{t}_{\mathrm{f}}$ & $\mathrm{h}$ & $\mathrm{d}$ & $\mathrm{r}$ & $\mathrm{d}_{2}$ & $\mathrm{l}_{2}$ & $\mathrm{~d}_{1}$ & $\mathrm{k}$ \\
\hline Value $(\mathrm{mm})$ & 225 & 10 & 260 & 17.5 & 260 & 177 & 24 & 19 & 100 & 31.7 & 10 \\
\hline
\end{tabular}

The particular type of push-out test specimen investigated in this paper is shown in Figure 1. It was designed according to the recommendations given in EN 1994-1-1 - Annexe B [6]. It includes one HEB 260 (S 355) steel section with a beam length of $750 \mathrm{~mm}$. The geometrical characteristics of the profile cross-section: web (A) and flanges (B), are presented in Figure 2 and Table 1. Two prefabricated slabs $(650 \mathrm{~mm}$ high, $600 \mathrm{~mm}$ wide, $150 \mathrm{~mm}$ thick) are symmetrically arranged on each side of the steel beam. Each slab includes a double reinforcement layer with $2 \times 4 \phi 10 \mathrm{~mm}$ longitudinal rebars of $550 \mathrm{~mm}$ length and $2 \times 5 \phi 10 \mathrm{~mm}$ transversal rebars of $520 \mathrm{~mm}$ length both in steel grade $S 500\left(\mathrm{f}_{\mathrm{y}}=500 \mathrm{~N} / \mathrm{mm}^{2}, \mathrm{f}_{\mathrm{u}}=550\right.$ $\mathrm{N} / \mathrm{mm}^{2}, E_{\mathrm{s}}=210000 \mathrm{~N} / \mathrm{mm}^{2}$ ). The two prefabricated slabs $(C)$ are connected to the steel girder flanges by means of 9 welded headed studs (E) (Figure 3 and Table 1) grouped inside a rectangular $(240 \times 280 \mathrm{~mm})$ recess. The arrangement of the studs satisfies the requirements of EN 1994-1, clause 6.6.5.7 on minimum spacing. The filling material used to achieve the connection had the same composition as the concrete $\mathrm{C} 40 / 50$ of the prefabricated slab, i.e. 
Cement CPA, CEMI, 0/14 TP : $405 \mathrm{~kg} / \mathrm{m}^{3}$, Aggregates 6,3/14: $966 \mathrm{~kg} / \mathrm{m}^{3}$, Sand 0/4: 834 $\mathrm{kg} / \mathrm{m}^{3}$, Admixtures: $1.62 \mathrm{~kg} / \mathrm{m}^{3}$, Water: $189 \mathrm{~kg} / \mathrm{m}^{3}$. The mean value of the compressive strength of the concrete slab and filling materials, obtained from testing of cylinders, is 56 $\mathrm{MPa}$. The specimen geometry is given in Figure 4.
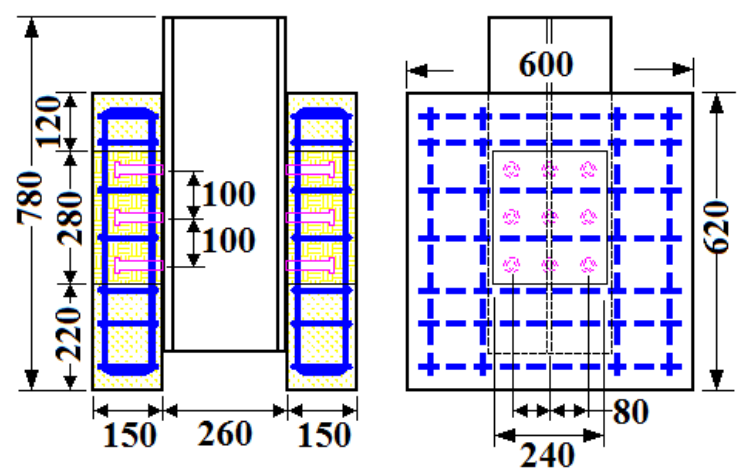

Figure 4. Geometry of the specimen (mm).

\subsection{Test setup, loading procedure and instrumentation}

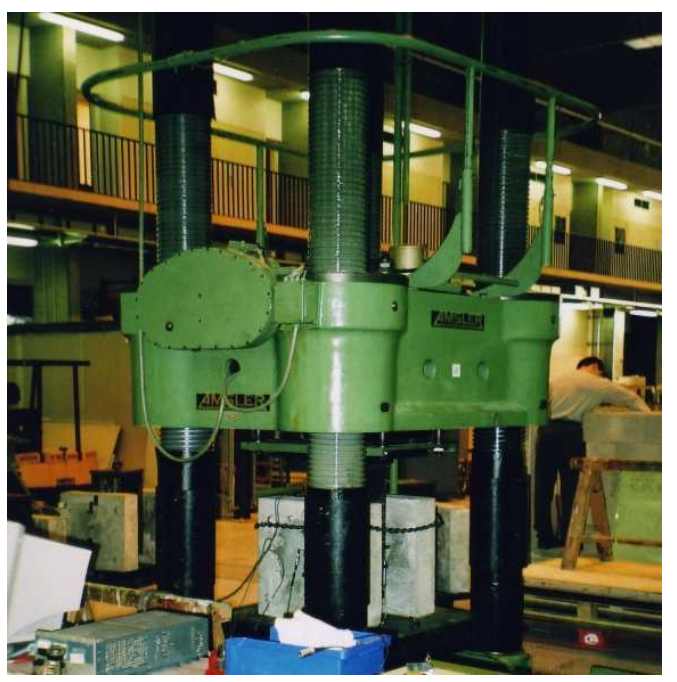

Figure 5: Test setup.

A $3000 \mathrm{kN}$ AMSLER four columns hydraulic testing machine (CEBTP Paris) was used by the Structures Laboratory of INSA - Rennes to test the specimen. A vertical load was applied at the top end of the steel beam, the two concrete slab lying at their bottom ends on an horizontal support.

The relative longitudinal displacement between each concrete slab and the steel beam was measured at two levels: at the upper end of the slabs and at the centroïd of the grouped studs; these two kinds of measurement have given very close results. The relative transverse displacement between the slabs and the steel beam was controlled at the upper and lower ends of the slabs.

The relative longitudinal displacement between the filling material and the concrete of the prefabricated slab was also measured using transducers fixed on the outside face of the two slabs. A total of 12 potentiometric transducers was used for the test.

\subsection{Test results}

Test results deal essentially with the load-slip curves as presented in Figure 11. In addition, it was observed the average relative displacement between the centre of the filling material and the recess wall as a function of the load remained low up to failure. Nevertheless, the bottom part deformation of the filling material block appears greater than the upper one. The relative transverse displacement between the slabs and the beam flange remains low. It is worth mentioning that it is difficult in such test to obtain experimental information about internal force transfers near the connection or at the steel-concrete interface. This is the reason for the development of a numerical model. 


\section{2D EQUIVALENT MODEL}

\section{1 “Zone-equivalence”" methodology}

The truly $3 \mathrm{D}$ problem is reduced to a $2 \mathrm{D}$ equivalent model using a "Zone-equivalence" methodology. This equivalence reduces the depth of the specimen along $\mathrm{Y}$ axis direction to equivalent material of $1 \mathrm{~mm}$ thickness taking into account the depth of each material encountered in this direction on one hand and the homogenization principle on second hand.

In plan $\mathrm{XY}$, the specimen is divided into zones defined by two series of bands in $\mathrm{X}$ and $\mathrm{Z}$ directions each time the nature or the thickness of material varies in $\mathrm{Y}$ direction (figure 6). Thus one can distinguish five zones indicates by L1, L2, L3, L4 and L5 : L1 corresponds to the web (A), L2 corresponds to the flanges (B) of the steel segment of depth $b_{f}$, L3 corresponds to the normal concrete (C) of the slab of depth B1, L4 corresponds to a part of the normal concrete of the slab of depth $2 \times \mathrm{B} 3$ plus the filling concrete (D)on the depth of the recess $B 2$ and L5 defined on the surface limited by the height and the diameter $\mathrm{d}_{2}$ of the connectors corresponds to the steel of the connector (E) on the depth $3 \times \mathrm{d}_{2}$ plus the filling concrete on the depth $\left(\mathrm{B} 2-3 \times \mathrm{d}_{2}\right)$ and a part of the normal slab concrete on the depth $2 \times \mathrm{B} 3$.

The real materials (A, B, C, D, E) are replaced by "zone-equivalent" materials of $1 \mathrm{~mm}$ thickness in $\mathrm{Y}$ axis direction. Especially for L4 this firstly requires that normal and filling concretes should be homogenized into filling concrete material and for L5 normal and filling concretes and the studs should be homogenized into steel material of the studs. The final equivalent materials for which the behavior models remain unchanged have new Young's moduli and yield stresses that are calculated as shown in table 2. In this table, the steel Young's moduli $\left(\mathrm{E}^{(\mathrm{A})}, \mathrm{E}^{(\mathrm{B})}\right.$ and $\mathrm{E}^{(\mathrm{C})}$ ) correspond respectively to the web and the flange of the steel segment and the studs; the slab concrete secant Young's modulus is $\mathrm{E}_{\mathrm{cm}}^{(\mathrm{C})}$ and the filling concrete is $\mathrm{E}_{\mathrm{cm}}^{(\mathrm{D})}$. The equivalence coefficient representing the homogenization is the ratio between the Young's moduli; for example, $\mathrm{n}_{\mathrm{eq}}^{\mathrm{C} \rightarrow \mathrm{E}}$ is the equivalence coefficient of normal concrete into steel material of the stud. While Young's moduli of each material (A, B, C, D and $\mathrm{E}$ - figure 1) are known, the equivalent Young's modulus of each zone (L1 to L5 - table 2) can be easily calculated. Final equivalent material for each zone is: (L1, A), (L2, B), (L3, C), (L4, D) and (L5, E). For each equivalent zone, the equivalent Young's modulus E (in $\mathrm{MPa} \times \mathrm{mm})$ can be written as follows:

$$
\mathrm{E}=\mathrm{E}^{(\mathrm{m})} \times\left(\sum \overline{\mathrm{B}}_{\mathrm{i}}\right)
$$

where:

$\mathrm{E}^{(\mathrm{m})}$ is the Young's modulus of the homogenized material of the concerned layer, $\sum \bar{B}_{i}$ is the sum of all included lengths in the concerned layer after homogenization. For example concerning the layer L5:

$$
\sum \overline{\mathrm{B}}_{\mathrm{i}}=\mathrm{n}_{\mathrm{eq}}^{\mathrm{C} \rightarrow \mathrm{E}} \times 2 \mathrm{~B} 3+\mathrm{n}_{\mathrm{eq}}^{\mathrm{D} \rightarrow \mathrm{E}} \times\left(\mathrm{B} 2-3 \mathrm{~d}_{2}\right)+3 \mathrm{~d}_{2}
$$

Remark: For reminder, $\mathrm{C}$ and $\mathrm{D}$ concretes must include the $1 \%$ of reinforcing steel. This will appear as a correction of the lengths B1, B2 and B3. The index R represents the reinforcing steel for which the Young's modulus is $\mathrm{E}^{(\mathrm{R})}$. 


$$
\begin{aligned}
& \mathrm{B} 1^{\text {new }}=\mathrm{B} 1\left[0.99+0.01 \mathrm{n}_{\mathrm{eq}}^{\mathrm{R} \rightarrow \mathrm{C}}\right] \\
& \mathrm{B} 2^{\text {new }}=\mathrm{B} 2\left[0.99+0.01 \mathrm{n}_{\mathrm{eq}}^{\mathrm{R} \rightarrow \mathrm{D}}\right] \\
& \mathrm{B} 3^{\text {new }}=\mathrm{B} 3\left[0.99+0.01 \mathrm{n}_{\mathrm{eq}}^{\mathrm{R} \rightarrow \mathrm{C}}\right]
\end{aligned}
$$

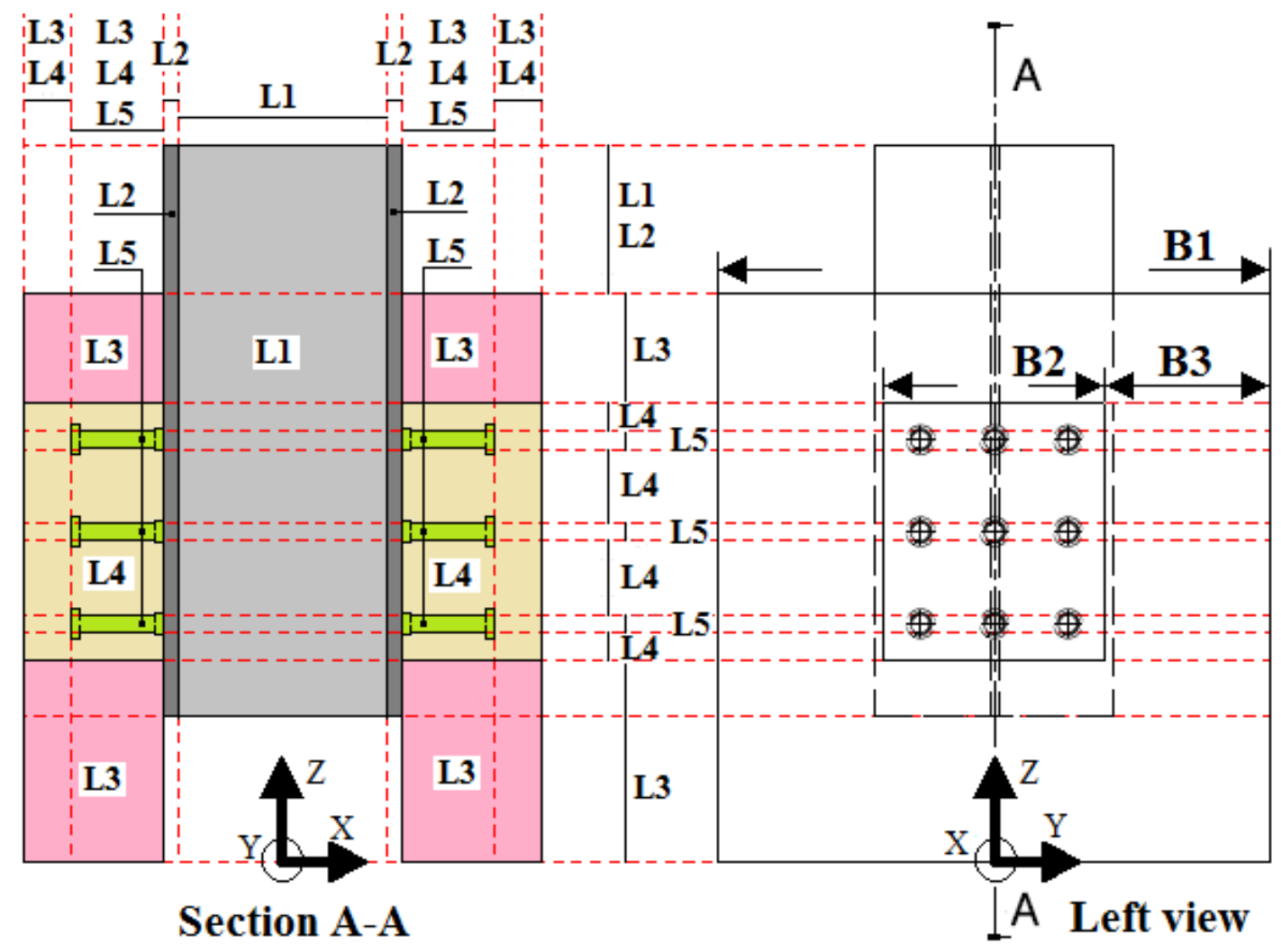

\begin{tabular}{|c|c|c|c|}
\hline Layer & $\begin{array}{l}\text { Materials } \\
\text { included }\end{array}$ & E calculation $(/ 1 \mathrm{~mm})$ & $\begin{array}{c}\text { Homogenized } \\
\text { material }\end{array}$ \\
\hline L1 & $\mathrm{t}_{\mathrm{w}}$ of $(\mathrm{A})$ & $\mathrm{E}^{(\mathrm{A})} \times \mathrm{t}_{\mathrm{w}}$ & $\begin{array}{l}\text { Web girder } \\
\text { (A) }\end{array}$ \\
\hline L2 & $b_{f}$ of $(B)$ & $E^{(B)} \times b_{f}$ & $\begin{array}{l}\text { Flange girder } \\
\text { (B) }\end{array}$ \\
\hline L3 & B1 of $(C)$ & $\mathrm{E}_{\mathrm{cm}}^{(\mathrm{C})} \times \mathrm{B} 1$ & $\begin{array}{c}\text { Classic } \\
\text { concrete }(\mathrm{C})\end{array}$ \\
\hline L4 & $\begin{array}{l}2 \mathrm{~B} 3 \text { of }(\mathrm{C}) \\
+\mathrm{B} 2 \text { of }(\mathrm{D})\end{array}$ & $\begin{array}{c}\mathrm{E}_{\mathrm{cm}}^{(\mathrm{D})} \times\left(\mathrm{n}_{\mathrm{eq}}^{\mathrm{C} \rightarrow \mathrm{D}} \times 2 \mathrm{~B} 3+\mathrm{B} 2\right) \\
\mathrm{n}_{\mathrm{eq}}^{\mathrm{C} \rightarrow \mathrm{D}}=\frac{\mathrm{E}_{\mathrm{cm}}^{(\mathrm{C})}}{\mathrm{E}_{\mathrm{cm}}^{(\mathrm{D})}}\end{array}$ & $\begin{array}{c}\text { Filling } \\
\text { concrete (D) }\end{array}$ \\
\hline L5 & $\begin{array}{c}2 \mathrm{~B} 3 \text { of }(\mathrm{C}) \\
+\left(\mathrm{B} 2-3 \mathrm{~d}_{2}\right) \text { of }(\mathrm{D}) \\
+3 \mathrm{~d}_{2} \text { of }(\mathrm{E})\end{array}$ & $\begin{array}{c}\mathrm{E}^{(\mathrm{E})} \times\left(\mathrm{n}_{\mathrm{eq}}^{\mathrm{C} \rightarrow \mathrm{E}} \times 2 \mathrm{~B} 3+\mathrm{n}_{\mathrm{eq}}^{\mathrm{D} \rightarrow \mathrm{E}} \times\left(\mathrm{B} 2-3 \mathrm{~d}_{2}\right)+3 \mathrm{~d}_{2}\right) \\
\mathrm{n}_{\mathrm{eq}}^{\mathrm{C} \rightarrow \mathrm{E}}=\frac{\mathrm{E}_{\mathrm{cm}}^{(\mathrm{C})}}{\mathrm{E}^{(\mathrm{E})}} \text { and } \mathrm{n}_{\mathrm{eq}}^{\mathrm{D} \rightarrow \mathrm{E}}=\frac{\mathrm{E}_{\mathrm{cm}}^{(\mathrm{D})}}{\mathrm{E}^{(\mathrm{E})}}\end{array}$ & Stud (E) \\
\hline
\end{tabular}

Figure 6. "Layer-equivalence" details.

Table 2. Equivalent Young's moduli. 


\subsection{Behavior models for equivalent materials}

The equivalent 2D model and the real 3D specimen should have same deformation. This means that the mechanical behaviors should be adapted. While the Young's moduli have been changed as shown previously, the yield stresses (in tension as well as in compression) should be multiplied by appropriate value of $\left(\sum \overline{\mathrm{B}}_{\mathrm{i}}\right)$ that depends on the concerned layer along $\mathrm{Z}$ axis.

- For the girder (web and flange) and the stud, an elastic-perfect plastic behavior is used in tension as-well-as in compression (figure 7.a).

- For the concrete slab (figure 7.b), the non-linear behavior combines Rankine cracking model in tension with Drücker-Prager plastic model in compression. This model needs the uniaxial stress strengths $\left(\overline{\mathrm{f}}_{\mathrm{ctm}}\right.$ and $\left.\overline{\mathrm{f}}_{\mathrm{cm}}\right)$ and the ultimate strains $\left(\varepsilon_{\mathrm{ctu}}\right.$ and $\left.\varepsilon_{\mathrm{cu}}\right)$, in tension and compression for both principal stress directions. In addition, it needs the concrete strength for a bi-axial compression $\left(\overline{\mathrm{f}}_{\mathrm{ccm}}\right)$. In case of cracking, one of the principal stresses reaches the concrete resistance in tension, the shear resistance is decreased reducing about $10 \%$ the shear modulus [27].

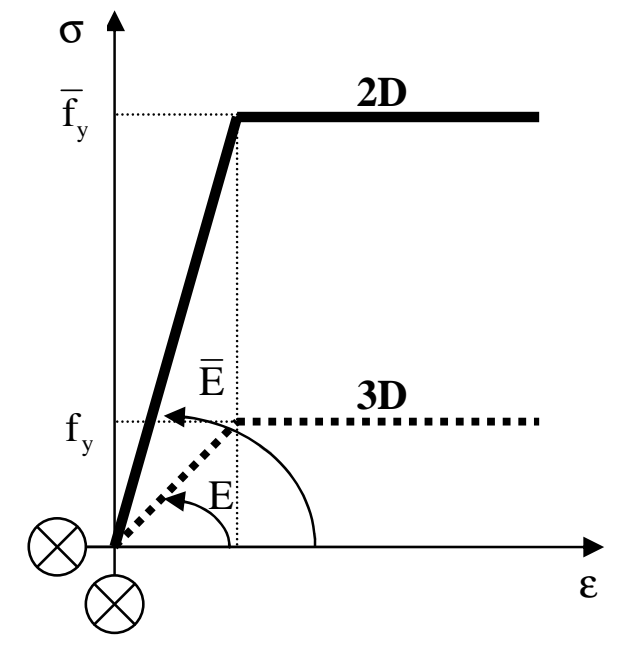

(a) - Girder and stud.

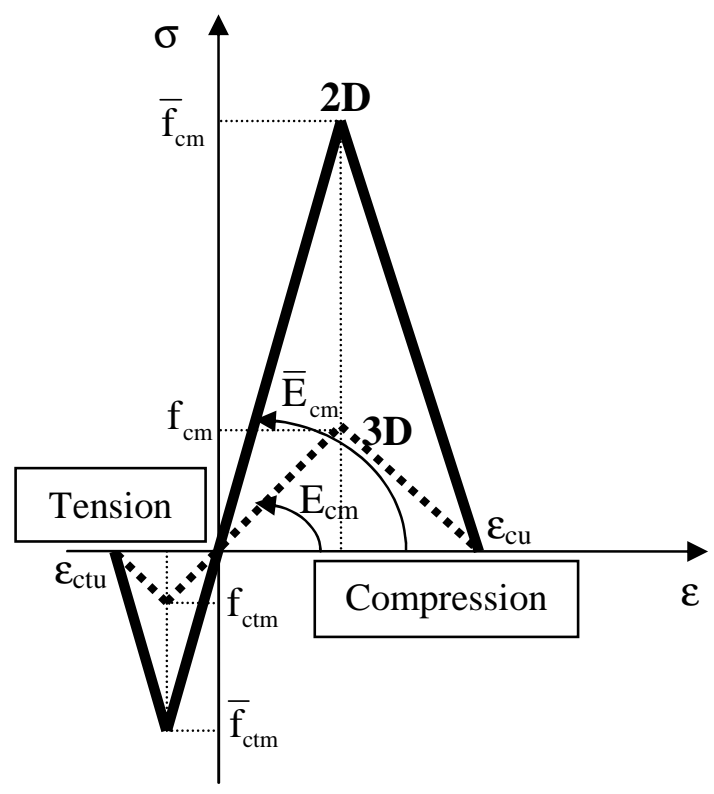

(b) - Concrete.

Figure 7. 2D-3D equivalent material behaviors.

\section{F.E. MODEL}

\subsection{Finite element type and mesh}

Taking advantage of the symmetry of the specimen, only a half of the push-out specimen was modeled (Figure 8). The calculation will be performed in plane stress. All the components of the push-out specimen were meshed with quadrangular F.E. (Figure 8). Contact friction elements were modeled by two lines of nodes. 


\subsection{Boundary and loading conditions}

Boundary conditions are shown in figure 8. Symmetric condition was applied to $\mathrm{Z}$ axis. According to experimental arrangement conditions (\$2), nodes at the base of the concrete slab were only restricted to move in Z-direction. The loading history of the specimen is given in figure 9; a Z-vertical displacement $\mathrm{W}$ is imposed at the top of the steel girder. It is pointed out that the numerical displacement values are the same as those measured during the experimental test. The load was measured as the total reaction acting under the base of the concrete slab. The studs welded to the flange girder are the only mechanical connection between the steel girder and the concrete panel. It is to point out that the FE model does not take into account the possible stud failure or concrete damage for a high value of vertical displacement. The maximum vertical displacement has been limited to $8 \mathrm{~mm}$.

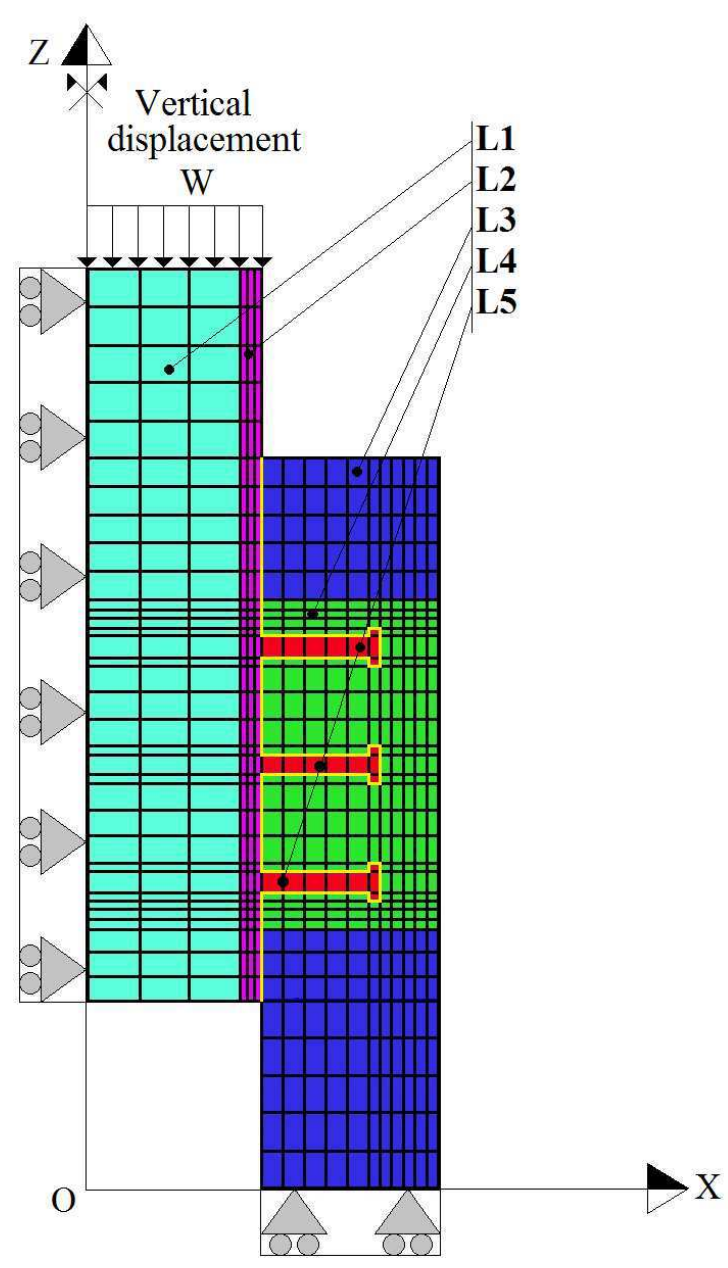

Figure 8. 2D F.E. model.

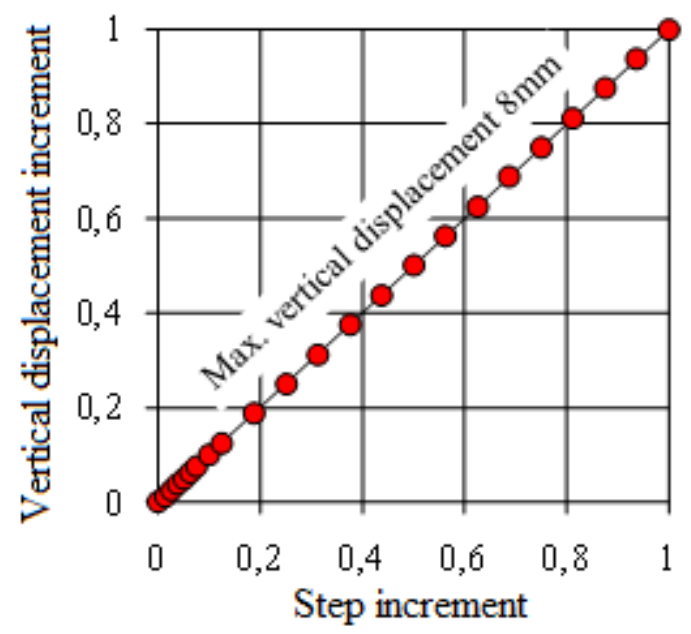

Figure 9. Loading history.

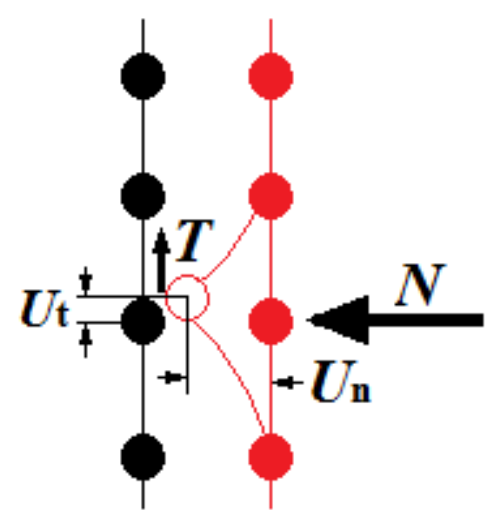

Figure 10. Contact variables.

\subsection{Contact friction finite elements}

Contact finite element formulation introduced in the modelling is based on the kinematic method: contact without penetration and friction conditions are described kinematically at the nodes. They are expressed in terms of displacements and forces. In accordance with figure 10, the normal displacement and corresponding normal force are $\left(U_{\mathrm{n}}, N\right)$ and tangent displacement with corresponding force are $\left(U_{\mathrm{t}}, T\right)$, both conditions can be written as follows: 
- Contact without penetration condition:

$$
\left(U_{n} \geq 0 \text { and } N \geq 0\right) \Rightarrow U_{n} N=0
$$

- Friction condition:

$$
\left(U_{t}>0 \Rightarrow-\vec{T}=\mu \vec{D}\right) \text { or } \quad\left(U_{t}=0 \Rightarrow-\vec{T}<\mu \vec{D}\right)
$$

where: $\mu=\frac{T}{N}$ is the friction coefficient and $\vec{D}=\frac{\vec{U}_{t}}{\left|\vec{U}_{t}\right|}$.

In practice, two lines of nodes must be created from two different materials (figure 10). These lines must be as close as possible that makes the contact between the closer front-nodes. This precaution ensures good convergence of the iterative process.

\section{CALIBRATION OF THE FE MODEL AGAINST EXPERIMENTAL TEST}

\subsection{Process and definitions}

In order to undertake the comparison with the results of the experimental test presented before, the numerical model must be adapted to the real conditions. It is pointed out that the comparison depends on several parameters; particularly the introduction or not of contact friction elements and boundary conditions. These different parameters will be introduced and discussed in the following paragraphs. For comparisons between numerical and experimental results load-slip curve per stud have been used; the slip being equal to the vertical displacement imposed at the top of the girder and the load being the resultant load calculated from node-Forces obtained by the numerical model at the top (action load) or at the bottom of the slab (reaction load) divided by the total number of studs which connects the slab to the flange steel girder in order to obtain an average force per stud. It is clear that in reality this force is not the same for all the studs (that will be clearly shown further), but it represents a variable that is easy to plot.

\subsection{Mechanical properties}

Reinforcing steel Young's modulus is $\mathrm{E}_{\mathrm{s}}=210000 \mathrm{MPa}$ representing $1 \%$ of the concrete volume and that the specimen is made of the same concrete C40/50 (B and C - figure 1). Introducing $\mathrm{f}_{\mathrm{ck}}$ as the characteristic value of the compressive strength, yield compression, yield tension and Young's modulus are respectively:

$$
\begin{aligned}
& \mathrm{f}_{\mathrm{cm}}=56 \mathrm{MPa}, \mathrm{f}_{\mathrm{ctm}}=0.3 \times \mathrm{f}_{\mathrm{ck}}^{2 / 3}=3.96 \mathrm{MPa}\left(\mathrm{f}_{\mathrm{ck}}=\mathrm{f}_{\mathrm{cm}}-8 \mathrm{MPa}\right) \\
& \mathrm{E}_{\mathrm{cm}}=22\left[\left(\mathrm{f}_{\mathrm{cm}}\right) / 10\right]^{0.3}=36900 \mathrm{MPa}
\end{aligned}
$$

According to equations 3, the lengths B1, B2 and B3 used in table 2 (with initial values: 600 $\mathrm{mm}, 240 \mathrm{~mm}$ and $190 \mathrm{~mm}$ respectively) must be corrected as follows:

$$
\mathrm{B}_{1}^{\text {new }}=\mathrm{B}_{1}\left[0.99+0.01 \frac{\mathrm{E}_{\mathrm{s}}}{\mathrm{E}_{\mathrm{cm}}}\right]=627 \mathrm{~mm}
$$




$$
\begin{aligned}
& \mathrm{B}_{2}^{\text {new }}=\mathrm{B}_{2}\left[0.99+0.01 \frac{\mathrm{E}_{\mathrm{s}}}{\mathrm{E}_{\mathrm{cm}}}\right]=251 \mathrm{~mm} \\
& \mathrm{~B}_{3}^{\text {new }}=\mathrm{B}_{3}\left[0.99+0.01 \frac{\mathrm{E}_{\mathrm{s}}}{\mathrm{E}_{\mathrm{cm}}}\right]=199 \mathrm{~mm}
\end{aligned}
$$

In table 3, E is the equivalent Young's modulus calculated with the formulas given in table 2 and knowing that real materials Young's moduli are: $210000 \mathrm{MPa}$ (girder and stud) and $36900 \mathrm{MPa}$ (concrete - Eq. 5). The Poisson's ratio $v$ is equal to 0.3 for the steel and 0.2 for the concrete. The yield stress of the steel profile is equal to $355 \mathrm{MPa}$ and the one of the stud material is equal to $500 \mathrm{MPa}$ (similar value was adopted in [21], [22] and [23]). Concerning the concrete slab, the strength in compression is equal to $56 \mathrm{MPa}$ and the one in tension is equal to $3.96 \mathrm{MPa}$.

Table 3. Equivalent 2D mechanical properties of material.

\begin{tabular}{|c|c|}
\hline Layer & Variable values $(\mathrm{MPa} \times \mathrm{mm}$ for E and $\mathrm{f})$ \\
\hline $\mathrm{L} 1$ & $\overline{\mathrm{E}}^{(\mathrm{L} 1)}=2100000, v^{(\mathrm{L} 1)}=0.3, \overline{\mathrm{f}}_{\mathrm{y}}^{(\mathrm{L} 1)}=3550$ \\
\hline $\mathrm{L} 2$ & $\overline{\mathrm{E}}^{(\mathrm{L} 2)}=54600000, v^{(\mathrm{L} 2)}=0.3, \overline{\mathrm{f}}_{\mathrm{y}}^{(\mathrm{L} 2)}=92300$ \\
\hline $\mathrm{L} 3$ & $\overline{\mathrm{E}}_{\mathrm{cm}}^{(\mathrm{L} 3)}=23178600, v^{(\mathrm{L} 3)}=0.2, \overline{\mathrm{f}}_{\mathrm{cm}}^{(\mathrm{L} 3)}=35176, \overline{\mathrm{f}}_{\mathrm{ctm}}^{(\mathrm{L} 3)}=2487$ \\
\hline $\mathrm{L} 4$ & $\overline{\mathrm{E}}_{\mathrm{cm}}^{(\mathrm{L} 4)}=23178600, v^{(\mathrm{L} 4)}=0.2, \overline{\mathrm{f}}_{\mathrm{cm}}^{(\mathrm{L} 4)}=35176, \overline{\mathrm{f}}_{\mathrm{ctm}}^{(\mathrm{L} 4)}=2487$ \\
\hline $\mathrm{L} 5$ & $\overline{\mathrm{E}}^{(\mathrm{L} 5)}=33045300, v^{(\mathrm{L} 5)}=0.3, \overline{\mathrm{f}}_{\mathrm{y}}^{(\mathrm{L} 5)}=60383$ \\
\hline
\end{tabular}

The rest of variables defining the concrete behavior model are given in table 4 . The same uniaxial behavior is considered for both principal stress directions.

Table 4. Rest of variable values for concrete behavior.

\begin{tabular}{|c|c|c|}
\hline$\varepsilon_{\mathrm{ctu}}=3 \overline{\mathrm{f}}_{\mathrm{ctm}} / \overline{\mathrm{E}}_{\mathrm{cm}}$ & $\varepsilon_{\mathrm{cu}}=10 \overline{\mathrm{f}}_{\mathrm{cm}} / \overline{\mathrm{E}}_{\mathrm{cm}}$ & $\overline{\mathrm{f}}_{\mathrm{ccm}}=1.2 \overline{\mathrm{f}}_{\mathrm{cm}}(\mathrm{MPa} \times \mathrm{mm})$ \\
\hline $3.2210^{-4}$ & $1.5110^{-2}$ & 42211 \\
\hline
\end{tabular}

\subsection{Contact finite element introduction}

\subsubsection{FE model without contact finite elements}

Before starting the comparison between numerical and experimental results, a first calculation has to proof the importance of the use of contact finite elements in the model. In this aim, figure 11 compares both result curves where the numerical one corresponds to the model without contact elements and the second is the experimental one. All materials are in constant contact during the loading history, the hypothesis of displacement continuity appears non- 
satisfactory because the numerical model seems to be too much more resistant than the reality. This result is especially due to the constant contact between the materials and the impossibility of separation whatever the load level (figure 12). The horizontal part of the curve over $1 \mathrm{~mm}$ of vertical displacement seems to occur when the top part of the steel segment begins to be deformed because the rest of the model is a "rigid" panel. The force distribution in the stud rows (given in percentage on the right side in figure 12) appears quasi uniformly distributed between the different stud rows.

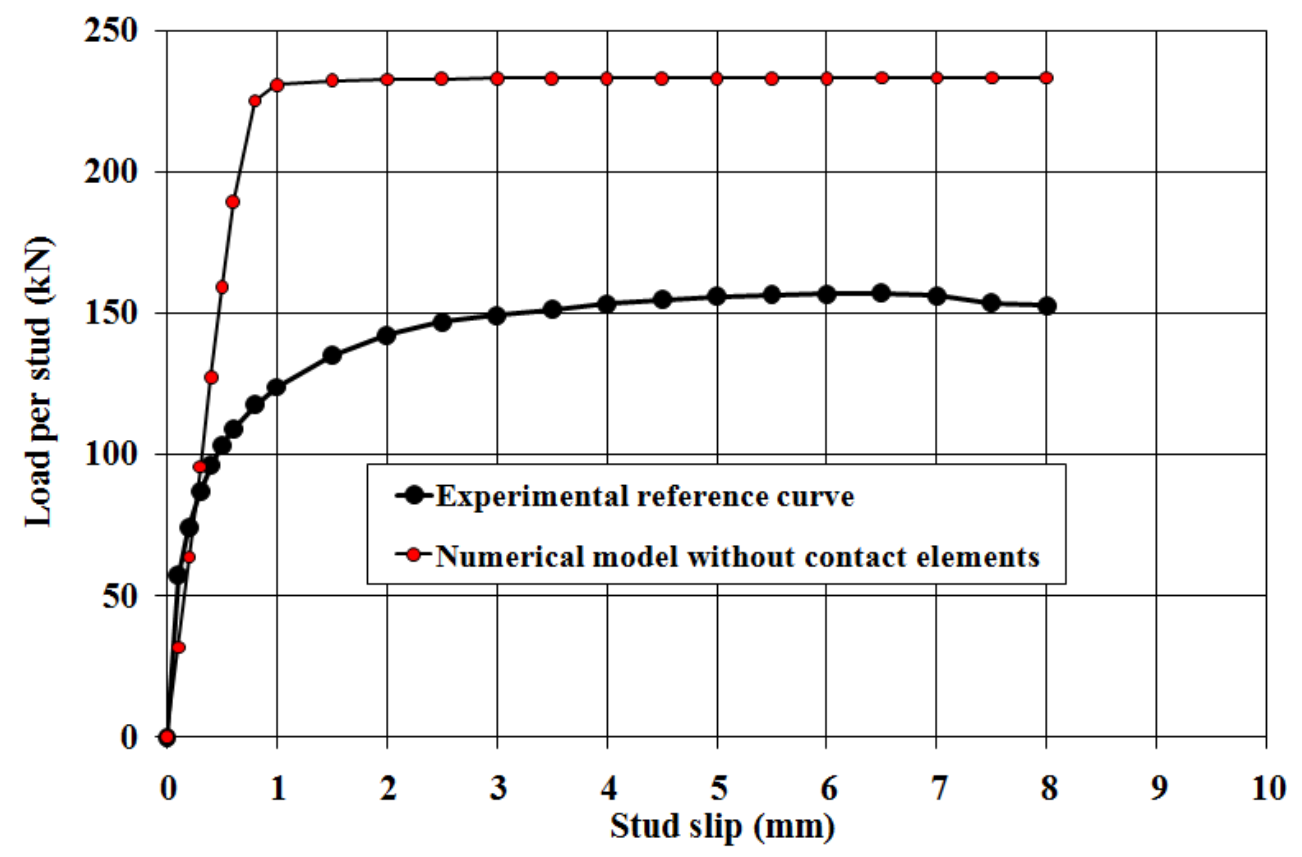

Figure 11. Importance of contact finite elements.
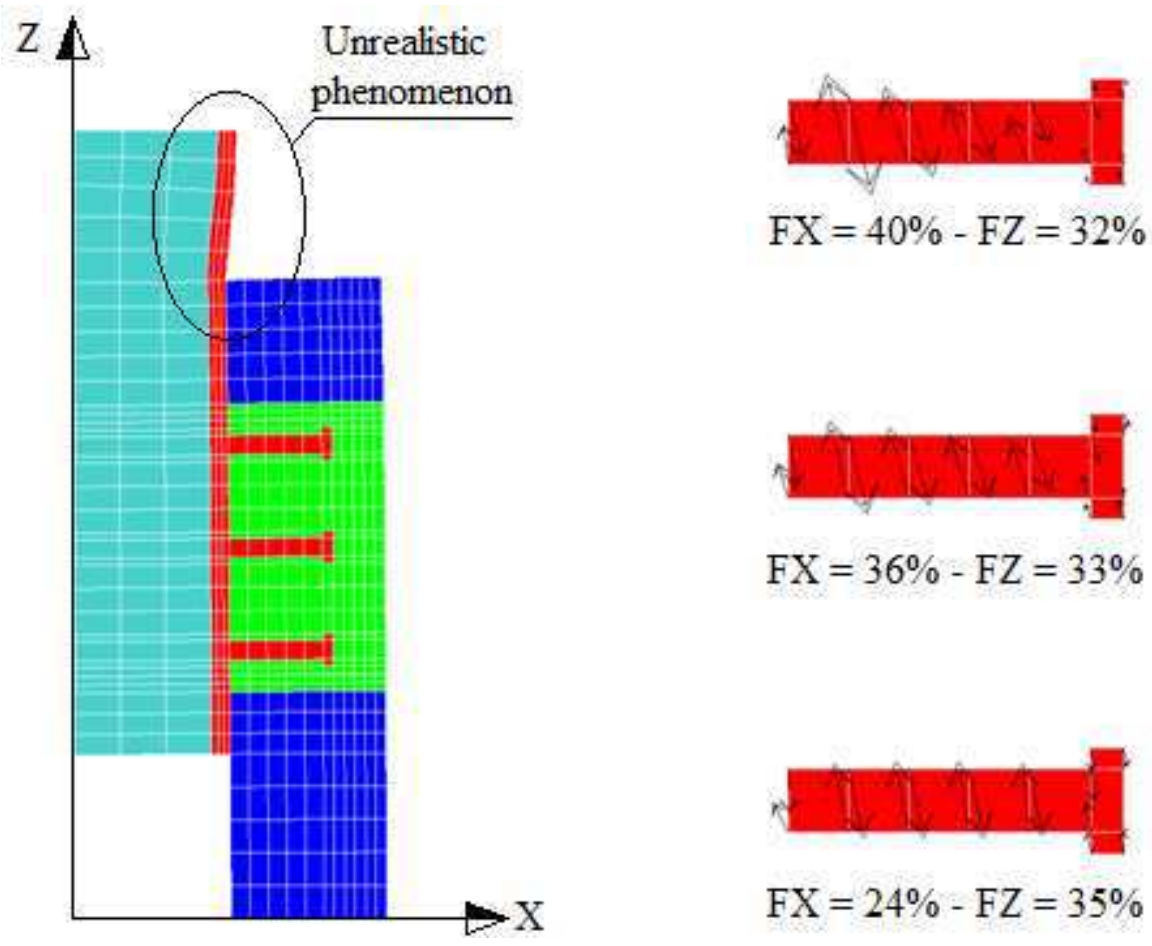

Figure 12. Model deformation and stud force percentages for imposed Z-vertical displacement $\mathrm{W}=3 \mathrm{~mm}$. 


\subsubsection{Introduction of contact finite elements between the concrete slab and the flange girder and the studs}

Contact finite elements have been introduced both between the concrete slab and the steel flange girder and the studs and the embedding concrete. At this stage of the study, the concrete slab is supported without any friction at its base. For this first investigation, the friction coefficients $\mu_{1}$ and $\mu_{2}$ are varying as follows $\mu_{1}=\mu_{2}=[0.0-0.1-0.2-0.3-0.4-$ 0.5]. It appears clearly in figure 13 that the numerical solution obtained with $\mu_{1}=\mu_{2}=0.3$ is closer to the experimental reference curve than the other values. It is pointed out that:

- The 2D approach gives initial stud stiffness less than the one calculated from the experimental results. This could be due to the fact that the chemical bond friction of the filling concrete at the beginning of the loading is not taken into account.

- Over $6 \mathrm{~mm}$ slip the numerical curve remains increasing while the experimental one decreases lightly; it is surely due, as said before, to the concrete damage at this loading level that is not taken into account in the numerical model. Nevertheless, until $6 \mathrm{~mm}$ slip (usual value for limit stud slip), the 2D model appears satisfactory.

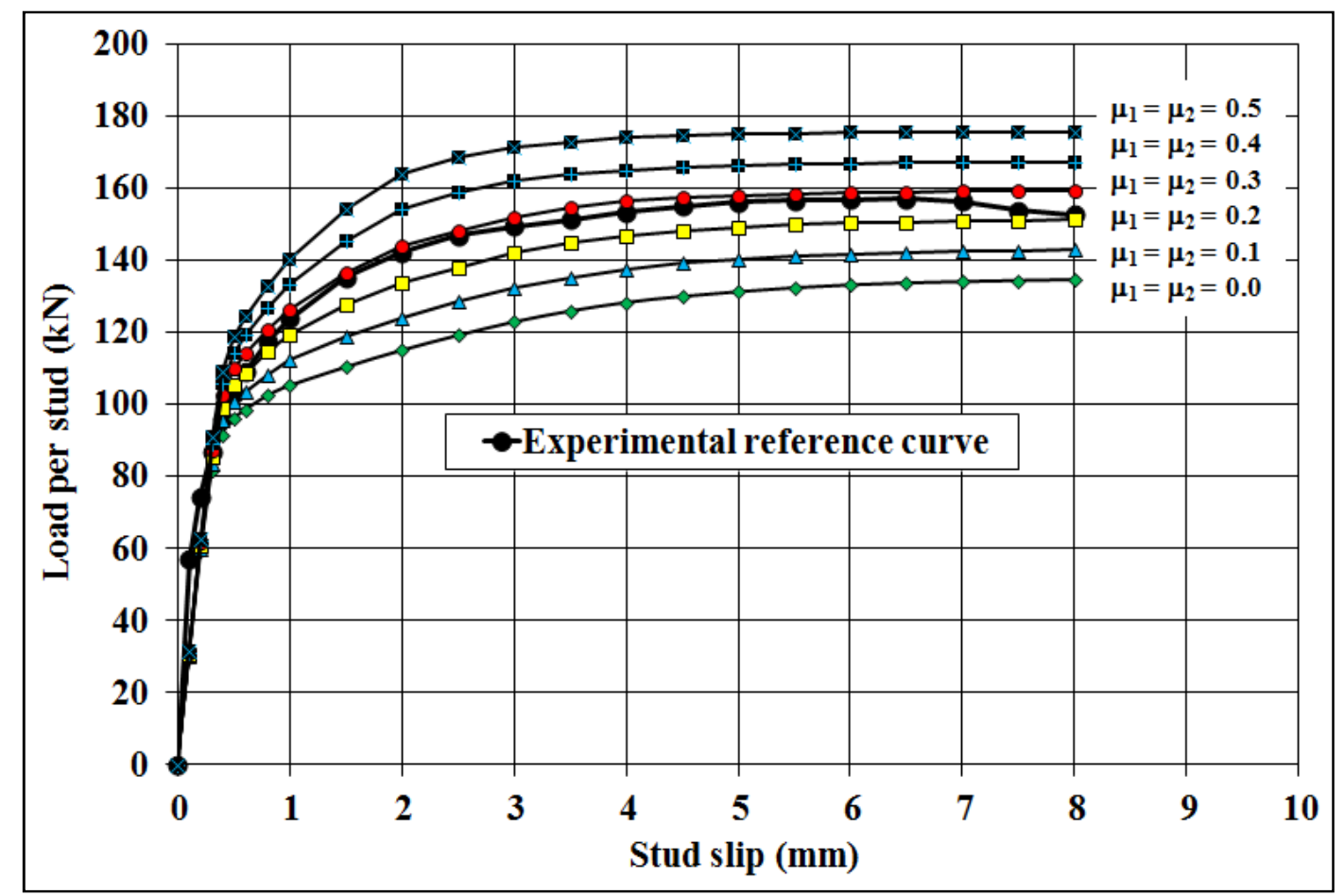

Figure 13. Comparison between experimental and numerical results.

\subsubsection{Calibration of the friction coefficient $\mu_{1}$ between the steel flange girder the concrete slab}

For this investigation, the friction coefficient between the steel flange girder and the concrete slab varies as follows $\mu_{1}=[0.0-0.1-0.2-0.3-0.4-0.5]$ while the friction coefficient $\mu_{2}$ between the studs and the embedding slab concrete remains equal to 0.3. It appears clearly in figure 14 that the numerical solution obtained with $\mu_{1}=0.2$ is closer to the experimental reference curve than the other values.

In figure 15 and table 5, it appears that the couple values of friction coefficients $\left(\mu_{1}=0.2\right.$ and $\mu_{2}=0.3$ ) seems to be the most probable one occurred during the push-out test. The average 
difference between this numerical solution and the experimental result does not exceed $1 \%$ that is enough satisfactory. This small average difference has been observed for the several imposed Z-vertical displacements: $\mathrm{W}=[1-2-3-4-5] \mathrm{mm}$.

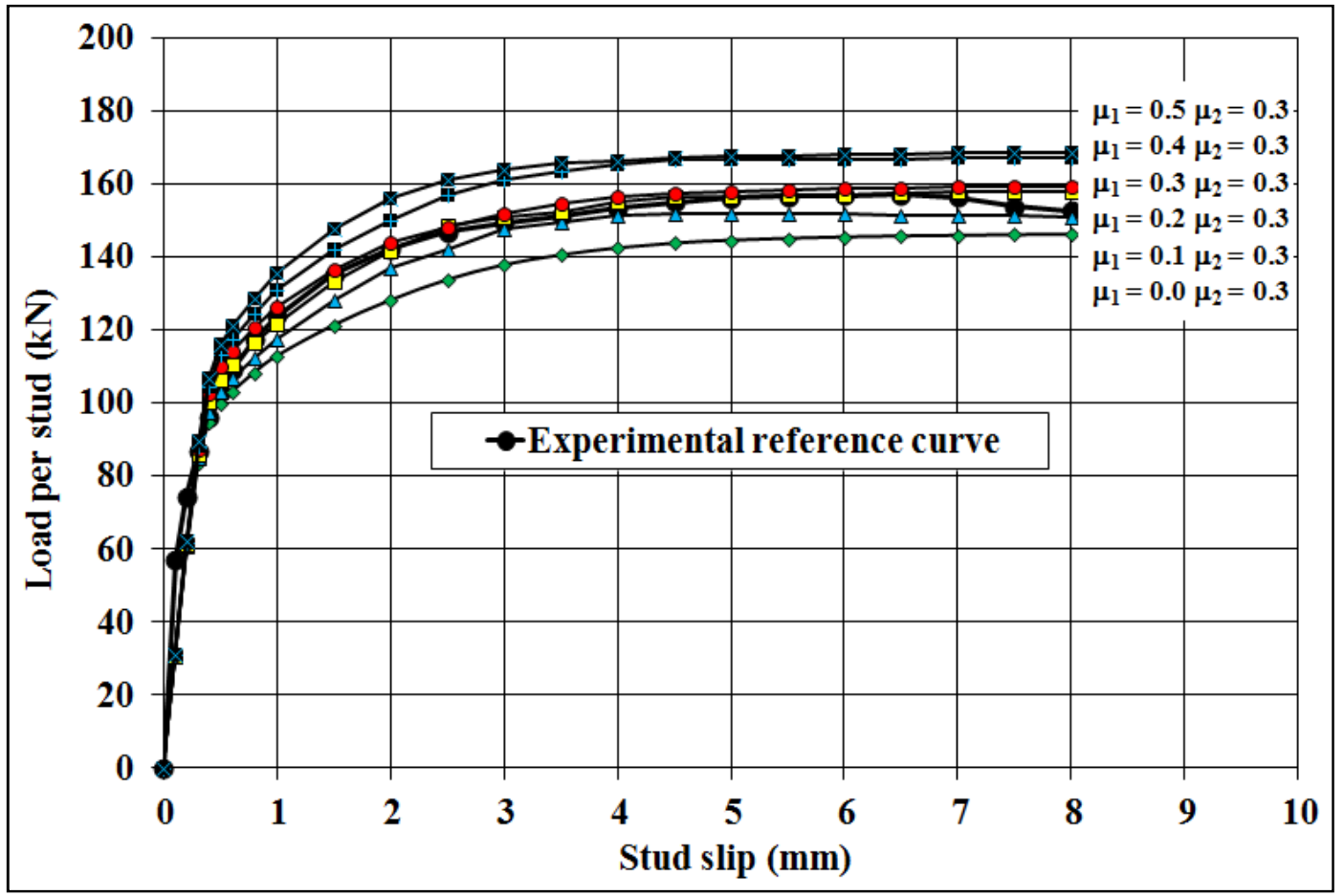

Figure 14. Friction coefficient $\mu_{1}$ influence (with $\mu_{2}=0.3$ ).

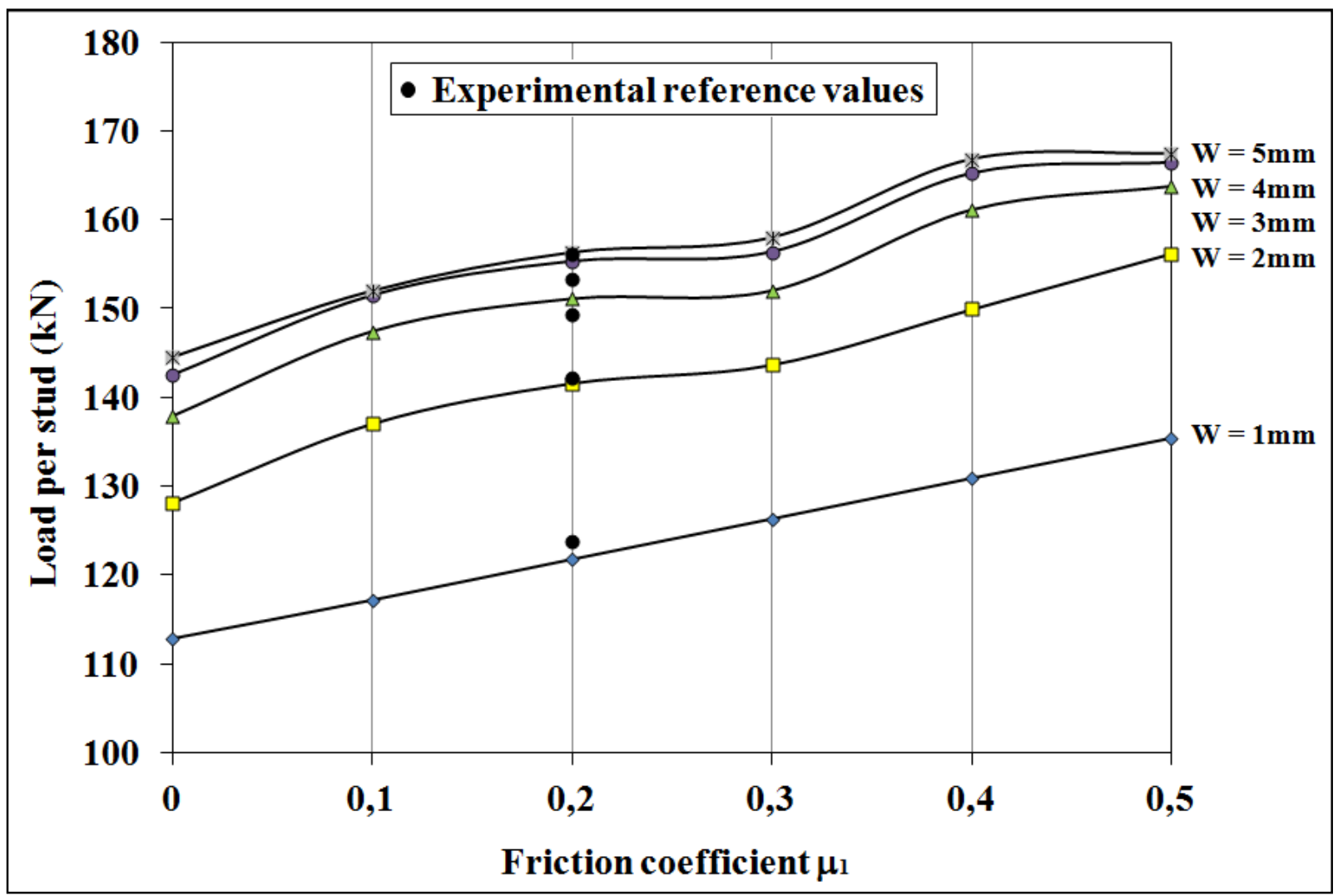

Figure 15. Results for different vertical displacements (with $\mu_{2}=0.3$ ). 
Table 5. Best value of $\mu_{1}$ (with $\mu_{2}=0.3$ ).

\begin{tabular}{|c|c|c|c|c|c|}
\hline \multicolumn{7}{|c|}{ Numerical results $(\mathrm{kN})$} \\
\hline$\mu_{1}$ & $\mathrm{~W}=1 \mathrm{~mm}$ & $\mathrm{~W}=2 \mathrm{~mm}$ & $\mathrm{~W}=3 \mathrm{~mm}$ & $\mathrm{~W}=4 \mathrm{~mm}$ & $\mathrm{~W}=5 \mathrm{~mm}$ \\
\hline 0 & 112 & 128 & 137 & 142 & 144 \\
\hline 0.1 & 117 & 137 & 147 & 151 & 152 \\
\hline 0.2 & 121 & 141 & 151 & 155 & 156 \\
\hline 0.3 & 126 & 143 & 152 & 156 & 157 \\
\hline 0.4 & 130 & 149 & 161 & 165 & 166 \\
\hline 0.5 & 135 & 156 & 163 & 166 & 167 \\
\hline
\end{tabular}

\begin{tabular}{|l|c|c|c|c|c|}
\hline Experimental & 123 & 142 & 149 & 153 & 156 \\
\hline
\end{tabular}

\begin{tabular}{|c|c|c|c|c|c|c|}
\hline \multirow{2}{*}{$\frac{\mu_{1}}{0}$} & \multicolumn{5}{|c|}{ Difference between numerical and experimental (\%) } & \multirow{2}{*}{$\begin{array}{c}\begin{array}{c}\text { Average } \\
\text { difference }\end{array} \\
8.1 \\
\end{array}$} \\
\hline & 8.8 & 9.8 & 7.6 & 7.0 & 7.3 & \\
\hline 0.1 & 5.3 & 3.6 & 1.2 & 1.1 & 2.6 & 2.8 \\
\hline 0.2 & 1.6 & 0.4 & 1.2 & 1.3 & 0.2 & 0.9 \\
\hline 0.3 & 2.0 & 1.0 & 1.8 & 2.0 & 1.2 & 1.6 \\
\hline 0.4 & 5.7 & 5.4 & 7.9 & 7.7 & 6.8 & 6.7 \\
\hline 0.5 & 9.3 & 9.8 & 9.7 & 8.5 & 7.2 & 8.9 \\
\hline
\end{tabular}

\subsubsection{Calibration of the friction coefficient $\mu_{2}$ between the studs and the concrete}

It is possible now to vary the friction coefficient $\mu_{2}$ (between the studs and the concrete) and keeping constant $\mu_{1}$ and equal to 0.2 (between the girder flange and the concrete). Figure 16 shows that the couple $(0.2-0.3)$ of friction coefficients highlighted in table 5 remains the best result.

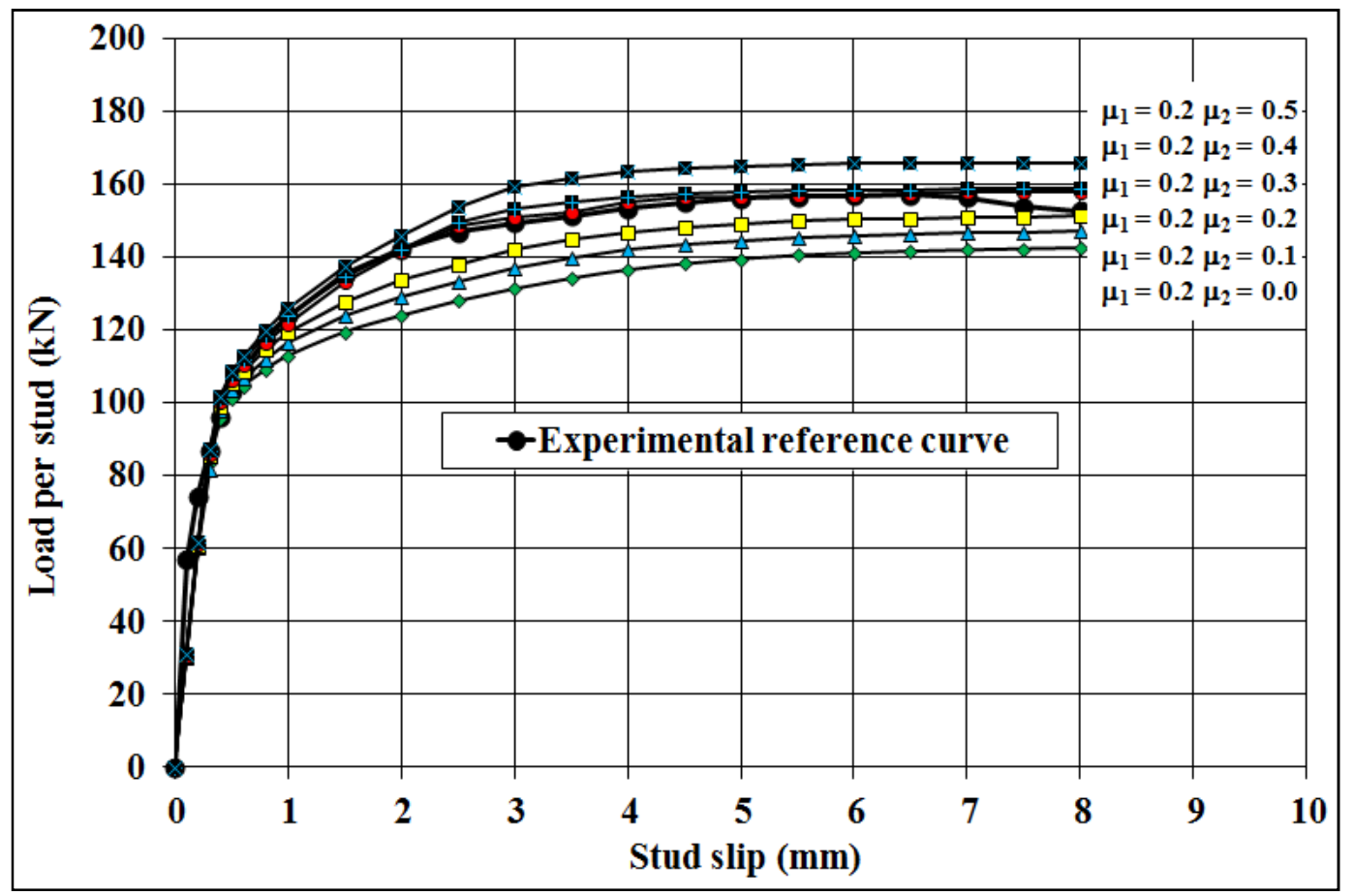

Figure 16. Friction coefficient $\mu_{2}$ influence (with $\mu_{1}=0.2$ ). 


\subsubsection{Stress results}

Keeping the couple of friction coefficients $\mu_{1}=0.2$ and $\mu_{2}=0.3$ and Z-vertical restricted displacement at the base of the concrete slab, isovalors of $\sigma_{\mathrm{xx}}, \sigma_{\mathrm{zz}}$ and $\sigma_{\mathrm{xz}}$ shown in figures 17.a, 17.b and 17.c, respectively, correspond to the real stresses (MPa) calculated using the values of equivalent stresses (MPaxmm). For example, the equivalent vertical compression stress obtained by the model at the top of the flange is : - $58300 \mathrm{MPa} \times \mathrm{mm}$, the flange dimension along Y-axis is $260 \mathrm{~mm}$, so the real stress is : - $224 \mathrm{MPa}$ (figure 17.b).

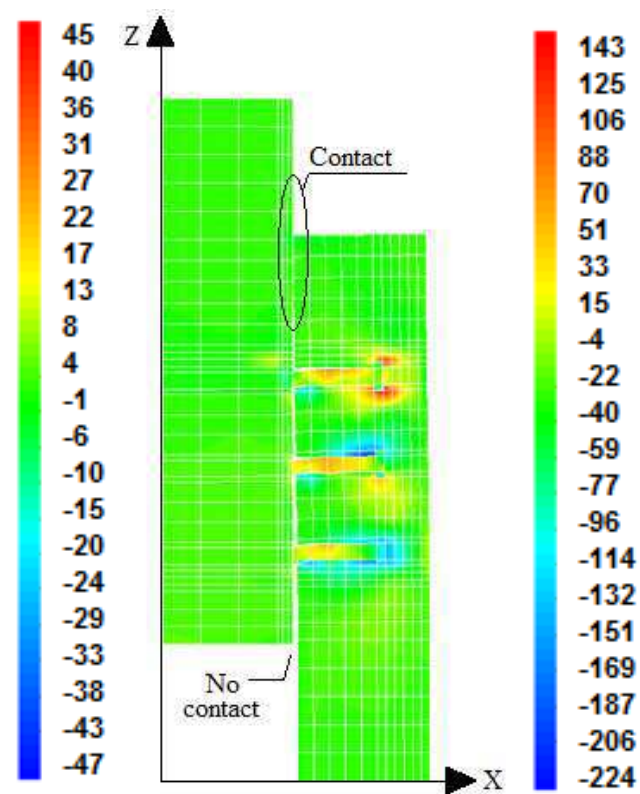

$\mathrm{a}-\sigma_{\mathrm{xx}}(\mathrm{MPa})$

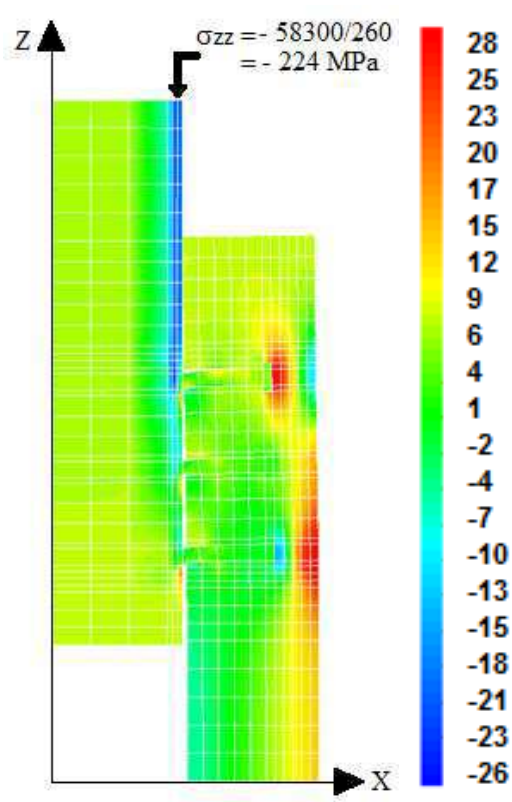

$\mathrm{b}-\sigma_{\mathrm{zz}}(\mathrm{MPa})$

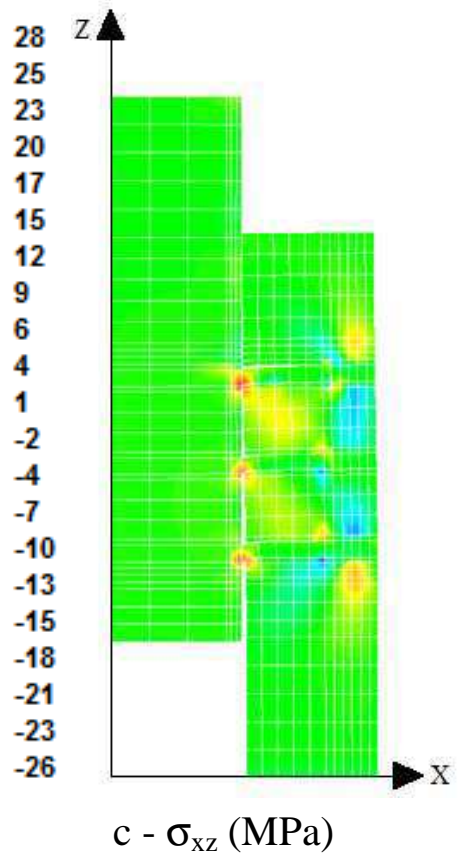

Figure 17. Stress isovalors plotted for the whole specimen for a Z-vertical displacement $\mathrm{W}=$ $3 \mathrm{~mm}$ and friction coefficients: $\mu_{1}=0.2, \mu_{2}=0.3$. No restraint in X-direction at the base of the concrete slab.

- In figures 17.a, 17.b and 17.c, one can observe that at the top of the specimen, the slab concrete comes in contact with the steel flange while at the bottom it moves away. The friction between the concrete slab and the steel flange is then mobilized at the top of the specimen as soon as there is contact between both materials. The separation between the slab and the flange increases gradually with the increment of the imposed vertical displacement.

- Figure 17.a shows that all stud rows are in tension. According to the amplitude of the relative displacement between the concrete slab and the steel flange, tension forces in stud rows increase from the top raw to the bottom row. The observation of the distribution of normal stresses $\sigma_{\mathrm{xx}}$ around the stud rows in Figure 17a shows that a flexural bending of the studs occurs simultaneously with the tension and shear forces in the studs.

- Figure 17.b with the normal stresses $\sigma_{\mathrm{zz}}$ shows a progressive transfer between the compressed steel girder and the concrete slab through the stud rows. The normal stress $\sigma_{\mathrm{zz}}$ value (-224 MPa) obtained by the FE model at the top of the girder is consistent with the experimental value observed for $3 \mathrm{~mm}$ vertical displacement and with the support reaction force at the base of the slab given by the FE model. 
- Figure 17.c shows that the shear stresses are mainly located at the base of the studs. Shear bands appear between the stud rows starting just below the stud heads of a given row to the base of the adjoining stud row. This observation is consistent with the concrete cone failure mode observed in this part of the push-out specimen when concrete failure occurs.

\subsection{Boundary support conditions at the base of the concrete slab}

Observing figures 17.a, 17.b and 17.c, one can wonder whether the boundary support conditions adopted at the base of the concrete slab may have an influence on the numerical stress and displacement results. To recall that, according to experimental test conditions, only $\mathrm{Z}$-vertical displacements have been restrained keeping free the $\mathrm{X}$-horizontal ones on the support at the base of the concrete slab. For that, the same type of contact elements than the ones used previously have been introduced in the model between the base of the concrete slab and the support with a friction coefficient value $\mu_{3}=0.25$. The results of this new modeling are presented in figures $18 \mathrm{a}-\mathrm{b}-\mathrm{c}$. No significant changes were observed compared to the boundary conditions adopted previously. One can see on these figures than the relative horizontal displacement between the base of the slab and the support is equal to the gap observed between the slab and the bottom of the steel segment. For other values of $\mu_{3}$, ranged between 0.25 and 0.5 , no significant plane stress changes were observed throughout the specimen.

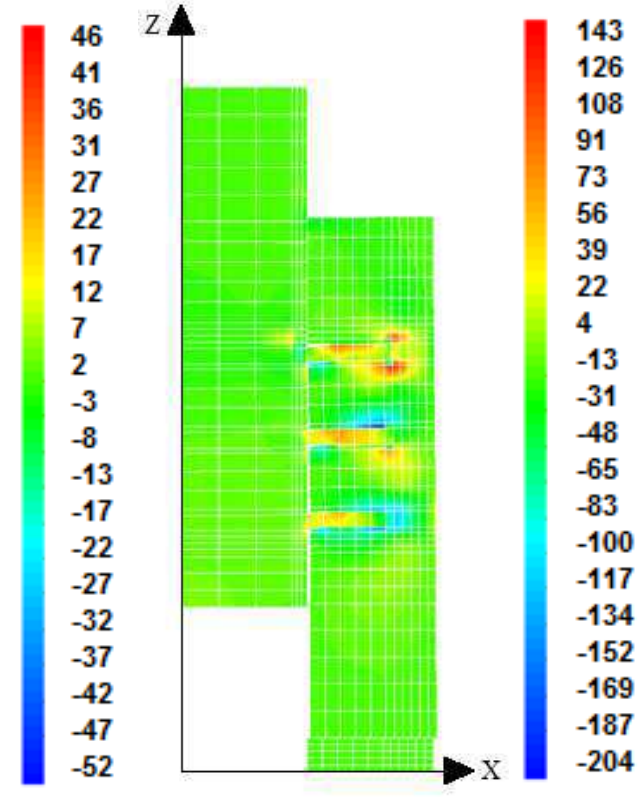

$\mathrm{a}-\sigma_{\mathrm{xx}}(\mathrm{MPa})$

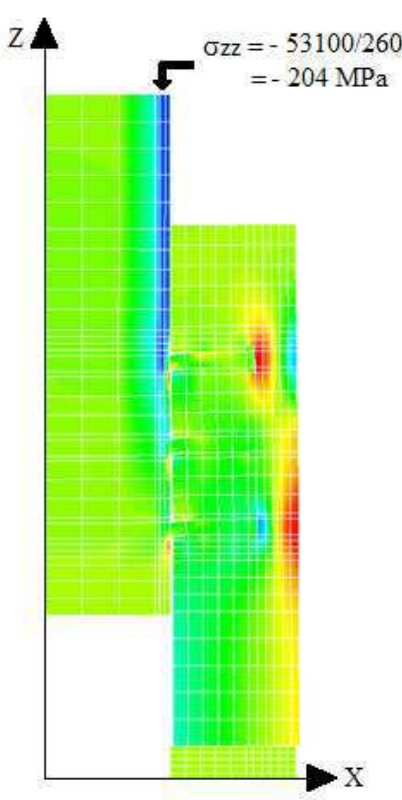

$\mathrm{b}-\sigma_{\mathrm{zz}}(\mathrm{MPa})$

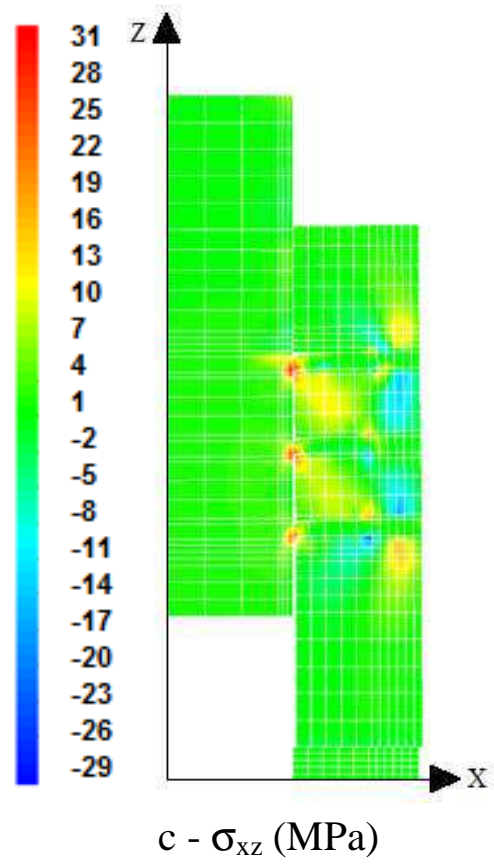

Figure 18. Stress isovalors plotted for the whole specimen for a Z-vertical displacement $\mathrm{W}=$ $3 \mathrm{~mm}$ and friction coefficients: $\mu_{1}=0.2, \mu_{2}=0.3$ and $\mu_{3}=0.25$.

While considering now the situation of a total restraint of $\mathrm{Z}$ and $\mathrm{X}$ displacements at the base of the concrete slab, we obtain the results presented in figure 19. Compared to the previous stress distribution obtained for no or partial restraints of X-displacements at the base of the concrete slab, we observe several changes: in figure 19.a, the flexural bending of the studs seems to be more important than previously (confirmed by displacements observed in figures 
19.a,b,c), in figure 19.b, the vertical stress distribution at the contact between the base of the slab and its support is inverted (with the inversion of the bending moment). In figure 19.c, the shear stress action is more located near the base of the stud rows and all the bottom part of the slab just below the bottom stud row is in shear due to the X-displacement restraint at the base of the slab.

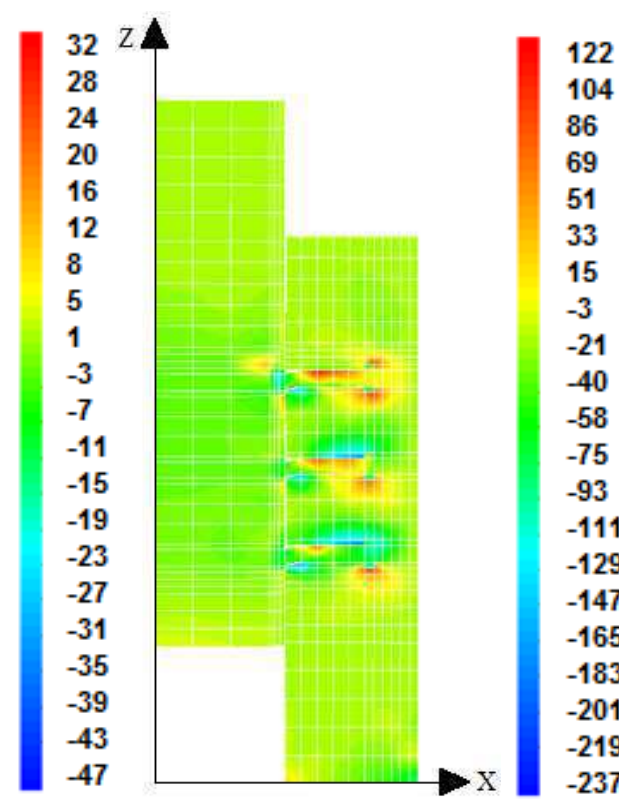

$\mathrm{a}-\sigma_{\mathrm{xx}}(\mathrm{MPa})$

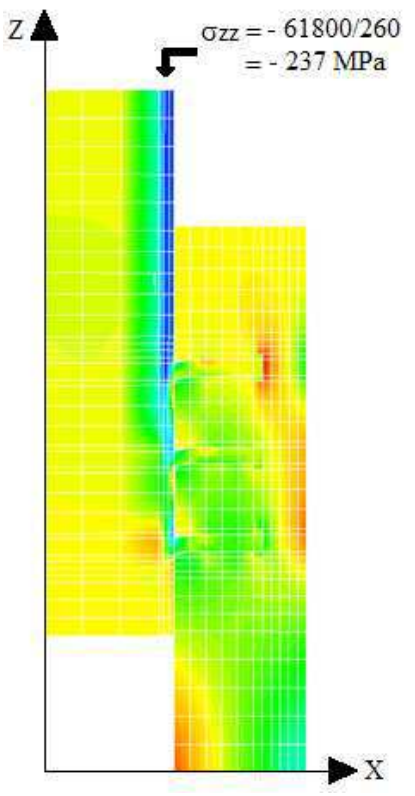

$\mathrm{b}-\sigma_{\mathrm{zz}}(\mathrm{MPa})$
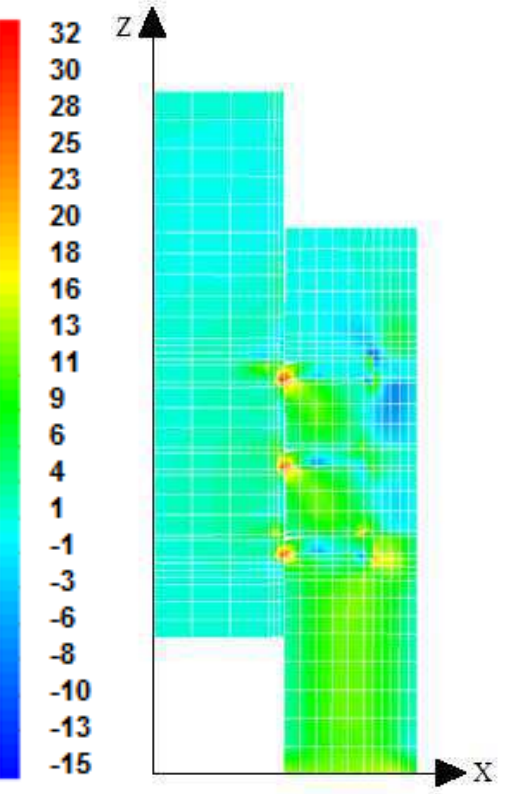

$\mathrm{c}-\sigma_{\mathrm{xz}}(\mathrm{MPa})$

Figure 19. Stress isovalors plotted for the whole specimen for a Z-vertical displacement $\mathrm{W}=$ $3 \mathrm{~mm}$, friction coefficients: $\mu_{1}=0.2$ and $\mu_{2}=0.3$ and a total restricted from moving displacements in $\mathrm{Z}$ and $\mathrm{X}$ directions at the base of the concrete slab.

\section{HORIZONTAL AND VERTICAL FORCES IN THE STUD ROWS}

Percentages of resultant forces along $\mathrm{X}$ and $\mathrm{Z}$ directions transmitted by a given stud row are calculated by dividing the resultant force transmitted by one stud row by the total resultant force along $\mathrm{X}$ and $\mathrm{Z}$ directions of all stud rows, respectively. The percentages thus calculated are given in figure 20 for an imposed displacement $\mathrm{W}=3 \mathrm{~mm}$.

For other values of imposed Z-displacements, in the case of no X-displacement restraint at the base of the concrete slab (Figure 20-a), percentage values, plotted in figures 21 and 22, appear quite the same whatever the imposed displacement level.

For a partial X-displacement restraint at the base of the concrete slab with a friction coefficient equal to 0.25 , the calculated percentages given in figure 20 -b are not very different from the ones obtained in the case of no X-displacement restraint. For higher friction coefficient values $\mu_{3}$ at the base of the concrete slab ranged between 0.25 and 0.9 even going to full X-displacement restraint (figure 20-c), only small change was observed between the percentage results with a small tendency towards a reduction of the variation between the forces transmitted by the stud rows. 
Comparing percentages obtained in figure 20 to corresponding ones in figure 12, the influence of the presence of contact friction elements appears clearly as the more important parameter to be introduced in the numerical model. There is a large difference between the percentages of horizontal and vertical forces at the studs' rows. The percentage of horizontal and vertical forces at the bottom row is greater than $50 \%$ of the total forces.

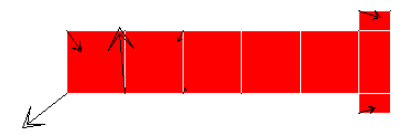

$\mathrm{FX}=15 \%-\mathrm{FZ}=11 \%$

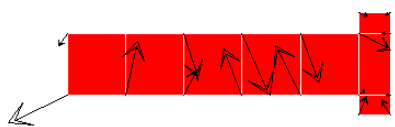

$\mathrm{FX}=34 \%-\mathrm{FZ}=30 \%$

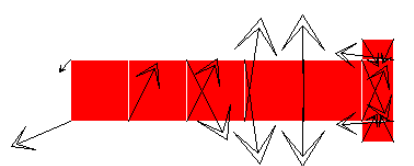

$\mathrm{FX}=51 \%-\mathrm{FZ}=59 \%$

$\mathrm{a}-$ No base restraint

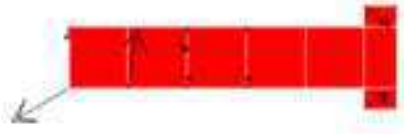

$\mathrm{FX}=15 \%-\mathrm{FZ}=15 \%$

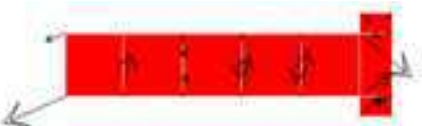

$\mathrm{FX}=33 \%-\mathrm{FZ}=32 \%$

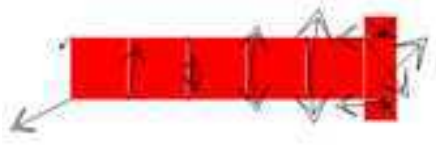

$\mathrm{FX}=52 \%-\mathrm{FZ}=53 \%$

b - Partial base restraint

(Friction coefficient $\mu_{3}=0.25$ )

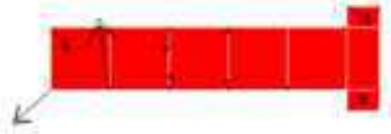

$\mathrm{FX}=20 \%-\mathrm{FZ}=15 \%$

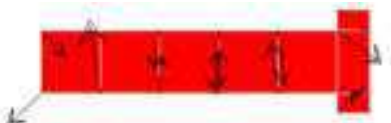

$\mathrm{FX}=31 \%-\mathrm{FZ}=36 \%$

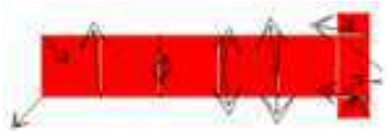

$\mathrm{FX}=49 \%-\mathrm{FZ}=49 \%$

$\mathrm{c}-$ Full base restraint

Figure 20. Percentage of forces FX and FZ per stud rows ( $\mathrm{W}=3 \mathrm{~mm})$.

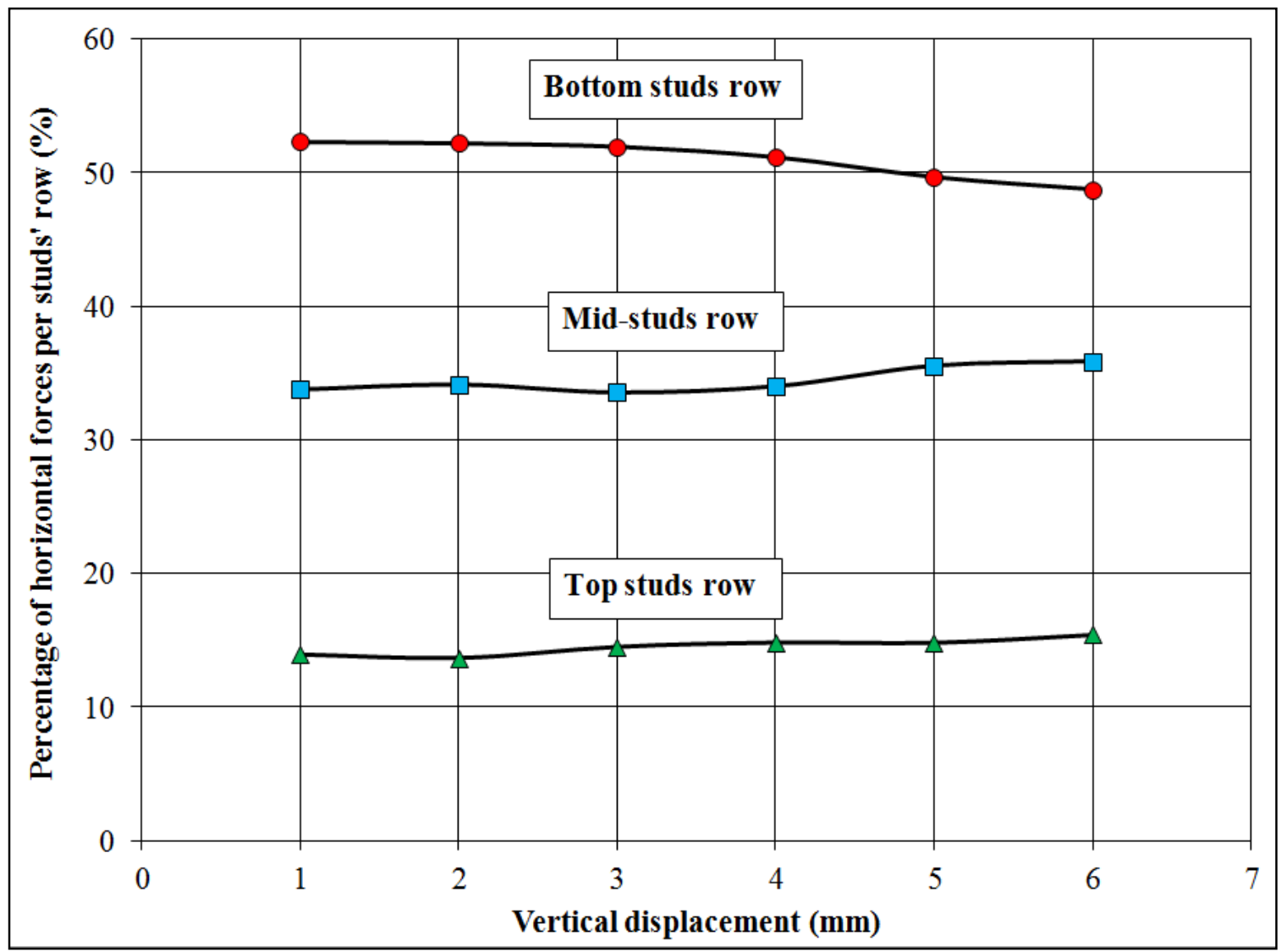

Figure 21. Percentage force FX per studs' row for different loading level. 


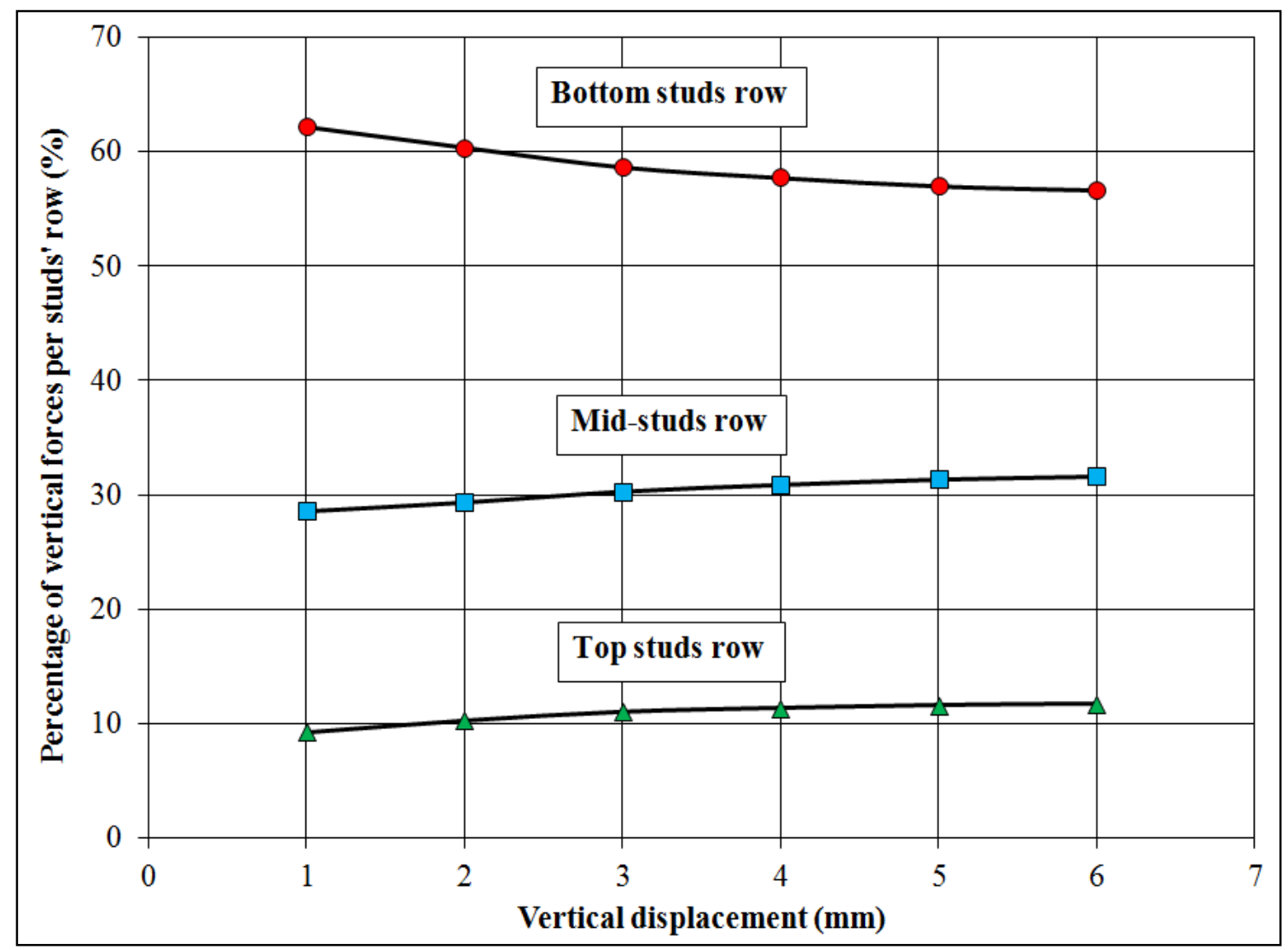

Figure 22. Percentage force FZ per studs' row for different loading level.

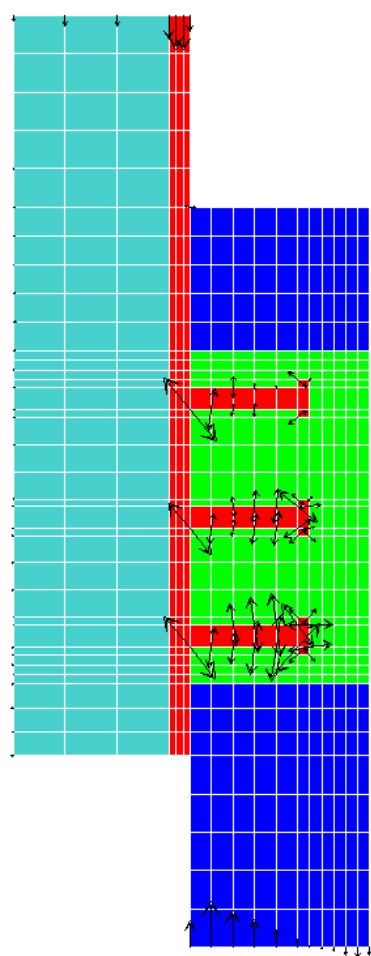

a - No base restraint

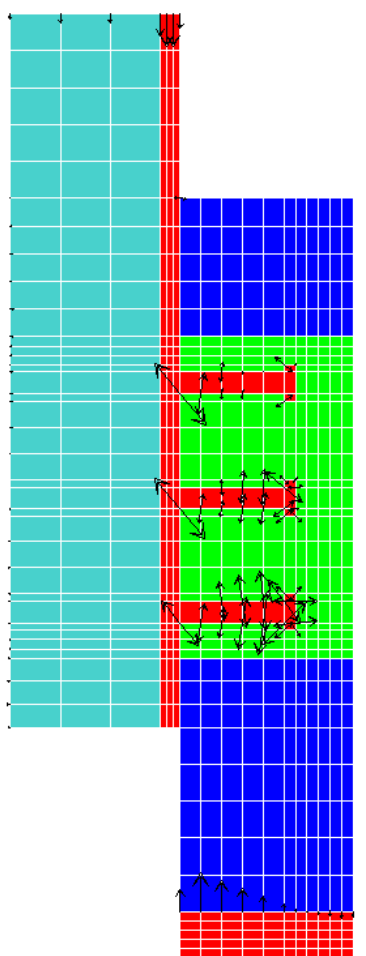

b - Partial base restraint

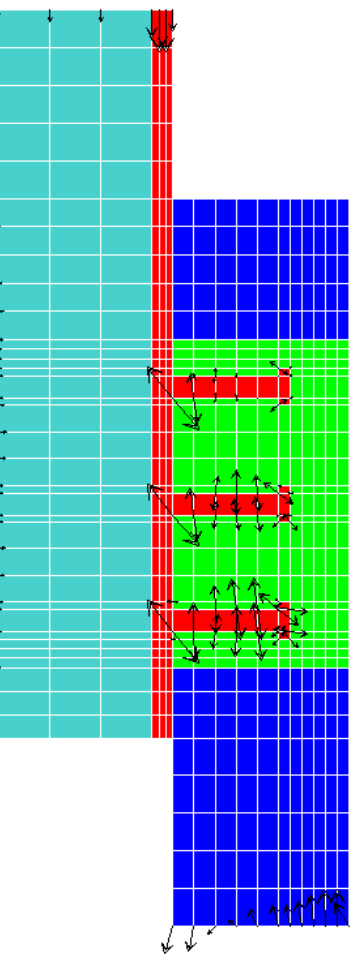

$\mathrm{c}-$ Full base restraint

(Friction coefficient $\mu_{3}=0.25$ )

Figure 23. Forces at the top of the steel girder, at the base of the concrete slab and at the studs rows $(\mathrm{W}=3 \mathrm{~mm})$. 
In addition to figure 20, figure 23 gives for the three boundary conditions, more information about the transmission of the internal forces inside the specimen through the stud rows and on the load distribution at the top of the steel girder and the base of the concrete slab, for an imposed Z-displacement $\mathrm{W}=3 \mathrm{~mm}$.

If the node-loads at the top of the steel girder are quite the same for the three considered boundary conditions, it is not the same at the base of the concrete slab where the node-force distribution is inverted between the no base restraint $\mathrm{X}$-displacement condition (figure 23a) and the full restraint $\mathrm{X}$-displacement base condition (figure 23b). However, this important change of the boundary conditions at the base of the concrete slab does not bring important modification of the forces transmitted through the stud rows (as seen previously).

\section{CONCLUSION}

In this paper a new 2D nonlinear finite element model has been proposed to analyze the behaviour of push-out specimens. It has been shown that the introduction of interface contact friction elements between the concrete slab and the steel flange girder and studs and embedded concrete leads to significant changing of the results in terms of stiffness, resistance and force distribution between the studs. On the other hand, a partial restraint of the horizontal displacements at the base of the concrete slab by means of the introduction of a contact friction element does not show a significant changing neither for stresses throughout the specimen nor for transmitted stud forces. On the other hand, a total restraint of horizontal displacements at the base of concrete slab reverses the normal force distribution at the base of the slab and leads to some changing of the stress distribution and transmitted forces throughout the specimen.

The validation of the proposed model against experimental data gives satisfactory results and leads to calibrate friction coefficients $\mu_{1}$ and $\mu_{2}$ concerned by the push-out test. A value of $\mu_{1}$ $=0.2$ was adopted for the friction coefficient between the studs and the concrete and a value of $\mu_{2}=0.3$ have been selected for the friction coefficient between the steel flange and the concrete slab. It has been observed that the possibility of separation between steel and concrete in the numerical model and the friction between the concrete and the flange of the girder had a strong importance on the results. A large difference between the normal and shear forces transmitted by the stud rows was observed.

It is noteworthy that these results are available only under the conditions of a conventional push-out test: vertical pure shear with no horizontal compression imposed on the external surface of the concrete slab. In the case of a steel concrete composite beam subjected to the weight of the slab and the overloads, some numerical simulations would be carried out to draw appropriate conclusions. It is probable that the friction would play a more pronounced role if the concrete slab was under compression. Guezouli et al. [28] studied the influence of the connection degree on the bending moment capacity of a steel concrete composite beams, this investigation should be reexamined to take into account the new results contains in this paper. Recently, researches have been undertaken by the French national project MIKTI [29] to study new shear connection types in composite bridges. These researches are mostly experimental and would benefit of numerical works. The proposed 2D model seems to be a 
good opportunity to develop new numerical investigations in these different fields. The perspective to extend the numerical work presented in this paper to a $3 \mathrm{D} \mathrm{FE}$ model is also considered.

\section{REFERENCES}

[1] Davies C., Tests on half-scale steel-concrete composite beams with welded shear connectors. The Structural Engineer, 47(1) (1969) 20-40, January.

[2] Johnson R.P., Composite Structures of Steel and Concrete Vol1, Beams, Slabs, Columns and Frames for Building. Oxford, Blackwell Scientific Publications (1971).

[3] Oehlers D.J., Splitting induced by shear connectors in composite beams". Journal of Structural Engineering. 115(2) (1989) 341-360, February.

[4] Johnson RP, Yuan H., Existing rules and new tests for stud shear connectors in troughs of profiled sheeting. Proceedings of the Institution of Civil Engineers, Structures and Buildings 128 (1998) 244-251.

[5] Johnson RP, Yuan H., Models and design rules for stud shear connectors in troughs of profiled sheeting. Proceedings of the Institution of Civil Engineers, Structures and Buildings 128 (1998) 252-263.

[6] EN 1994-1-1:2004: Eurocode 4: Design of composite and concrete structures - Part 1-1: General Rules and Rules for Buildings, European Committee for Standardization, 2004.

[7] American Institute for Steel Construction (AISC). Load and resistance factor design speciation for structural steel building. Chicago (IL): American Institute for Steel Construction; 1993.

[8] LEBET J-P., Comportement des ponts mixtes acier-béton avec interaction partielle de la connexion et fissuration du béton. PHD thesis, Federal Polytechnic School, Lausanne, Suisserland (1987).

[9] ROIK K., HANSWILLE G., Zur Dauerfestigkeit von Koptbolzendübeln bei Verbundträgern. Bauingenieur 62 (1987) 273-385.

[10] HIRAGI H., MATSUI S., MUTO K., Development of Favourable Stud Shear Connectors to Flexible Composite Actions. Journal of Structural Engineering, 44A (1998) 1485-1496.

[11] Hosaka T., Hiragi H., Koeda Y., Tachibana T., Watanabe Y., An experimental Study on Characteristics of Shear Connectors in Composite Continuous Girders for Railway Bridges. Journal of Structural Engineering, 44A (1998) 1497-1504.

[12] Okada J., Lebet J.-P., Strength and behaviour of grouped stud connectors. Proceedings of 6th ASCCS Conference, Los Angeles, USA, vol. 1, March 2000, p. 321-328. 
[13] Hanswille G. et al., Push-out Tests with Groups of Studs. ECSC Steel RTD Programme: Composite Bridge Design for Small and Medium Spans, Final report 7210-PR/113, Ch. 3 (2002) 3-1, 3-43.

[14] Lachal A., Aribert J-M. Demilecamps L., Shear behaviour of grouped stud connectors in precast slab: effects of filling material and recess arrangement. Proceedings of the 2nd International Symposium on Connections between Steel and Concrete, University of Stuttgart, Germany, vol. 2 (2007) 1233-1242.

[15] Oguejiofor E. C. and Hosain M. U., Numerical analysis of push-out specimens with perfobond rib connectors. Computers \& Structures Volume 62, Issue 4, February 1997, Pages 617-624.

[16] Al-Darzi S.Y.K., Chen A.R., Liu Y.Q., Parametric studies of push-out test with perfobond rib connector. China-Japan Joint Seminar on Steel and Composite Bridges, 16-17 janvier 2007

[17] Kim B., Wright H.D., Cairns R., The behaviour of through-deck welded shear connectors: an experimental and numerical study. Journal of Constructional Steel Research 57 (2001) 1359-1380.

[18] Johnson R.P., Oehlers D.J., Analysis and design for longitudinal shear in composite Tbeams. Proceedings of the Institution of Civil Engineers, Part 2 (1981) 989-1021.

[19] Jayas B.S., Hosain M.U., Behaviour of headed studs in composite beams: push-out tests. Canadian Journal of Civil Engineering 15 (1987) 240-253.

[20] Kalfas C., Pavlidis P., Load-slip curve of shear connectors evaluated by FEM analysis. International Conference, Composite Construction - Conventional and Innovative, Innsbruck, Austria, (1997) 151-156.

[21] El-lobody E., Lam D., Modelling of headed stud in steel-precast composite beams. Steel and Composite Structures, Vol. 2, No. 5 (2002) 355-378.

[22] El-lobody E., Young B., Performance of shear connection in composite beams with profiled steel sheeting. Journal of Constructional Steel Research 62 (2006) 682-694.

[23] Okada J., Yoda T., Lebet J.P., A study of the grouped arrangements of stud connectors on shear strength behavior. Journal of Structural Engineering and Earthquake Engineering, Vol. 23, No. 1, (2006) 75s-89s.

[24] Nguyen H.T., Kim S.E., Finite element modelling of push-out tests for large stud shear connectors. Journal of Constructional Steel Research 65 (2009) 1909-1920.

[25] Mirza O., Uy B., Effects of the combination of axial and shear loading on the behaviour of headed stud steel anchors. Engineering Structures 32 (2010) 93-105. 
[26] Guezouli, S, Yabuki, T, A user friendly program for continuous beams of composite bridges. International Colloquium on Stability and Ductility of Steel Structures (SDSS'06), Lisbon, September 6-8-2006.

[27] Alsafadi R., Displacement and Mixed-Based Finite Element Formulations for Threedimensional Corotational Beams, PhD thesis, National Institute of Applied Sciences, Rennes, October (2010), France.

[28] S. Guezouli, M. Hjiaj, and Q.H. Nguyen, 3-D F.E. Connection degree in composite continuous beams - Influence on the bending moment capacity, Eurosteel 2008, Gratz, Austria, Septembre 2008.

[29] Chabrolin, B, Hretz, T, Laravoire, J, Ponts Mixtes Acier-Béton - Un guide pour les ouvrage innovants. French National Project MIKTI, Presses des Ponts, 2010. 